

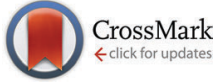

Cite this: Phys. Chem. Chem. Phys., 2016, 18, 17169

Received 12th November 2015, Accepted 3rd February 2016

DOI: $10.1039 / c 5 c p 06947 e$

www.rsc.org/pccp

\title{
Dissolved chloride markedly changes the nanostructure of the protic ionic liquids propylammonium and ethanolammonium nitrate $\dagger$
}

\author{
Thomas Murphy, ${ }^{a}$ Samantha K. Callear, ${ }^{b}$ Gregory G. Warr ${ }^{c}$ and Rob Atkin ${ }^{* a}$
}

\begin{abstract}
The bulk nanostructure of $15 \mathrm{~mol} \%$ propylammonium chloride (PACl) dissolved in propylammonium nitrate (PAN) and 15 mol\% ethanolammonium chloride (EtACl) in ethanolammonium nitrate (EtAN) has been determined using neutron diffraction with empirical potential structure refinement fits. For both the PAN:PACl and EtAN:EtACl mixtures, data for three different scattering contrasts were simultaneously fit, and the structures determined and compared to that of the pure ionic liquids. Strong electrostatic interactions between chloride and cation charged groups, as well as the alcohol moiety of EtAN, lead to marked changes in local ion packing that alter the liquid structure. In PAN, the addition of chloride modifies but does not significantly disrupt the bicontinuous amphiphilic nanostructure of the IL. Tight packing of ammonium groups around chloride favours a gauche conformer for the cation which shrinks the apolar domains and brings the terminal methyls nearer the polar domains. The weakly-clustered nanostructure of EtAN, a consequence of the terminal hydroxyl, is overwhelmed by strong chloridecation interactions. Ethanolammonium binds tightly to chloride in a monodentate fashion via either its alcohol or ammonium charge centre, or through both in a bidentate arrangement by adopting a gauche or eclipsed conformer.
\end{abstract}

\section{Introduction}

Ionic liquids (ILs) are salts with melting points less than $100{ }^{\circ} \mathrm{C}$. ILs are composed entirely of ions and often boast an array of desirable physiochemical properties, including high electrochemical stability, ${ }^{1}$ high thermal stability, ${ }^{2}$ low vapour pressure ${ }^{1,3,4}$ and the ability to dissolve both organic and inorganic substances. ${ }^{5}$ A vast number of ion structures can be employed to form ILs, which enables the properties of ILs to be tuned. These features make ILs both fundamentally intriguing ${ }^{6}$ and of great interest for advanced technological applications. ${ }^{7-12}$

Many ILs are nanostructured in the bulk ${ }^{13-18}$ and at interfaces. ${ }^{19-22}$ The IL nanostructure is a consequence of strong cohesive interactions between the charged moieties of the ions, leading to the formation of polar (charged) domains which solvophobically exclude cation alkyl chains into apolar regions. The polar and apolar domains percolate through the bulk in a bicontinuous sponge-like structure..$^{13,17,23-26}$ ILs comprised of

\footnotetext{
${ }^{a}$ Priority Research Centre for Advanced Fluids and Interfaces, The University of Newcastle, Callaghan, NSW 2308, Australia.E-mail: Rob.Atkin@newcastle.edu.au ${ }^{b}$ STFC, Rutherford Appleton Laboratory, Didcot, UK

${ }^{c}$ School of Chemistry, The University of Sydney, NSW 2006, Australia

$\dagger$ Electronic supplementary information (ESI) available. See DOI: 10.1039/ c5cp06947e
}

cations with short alkyl chains or polar functional groups do not form self-assembled nanostructures. Such an amphiphilic nanostructure is typically found in protic ILs when the cation alkyl chain is $\mathrm{C}_{2}$ or longer, ${ }^{23}$ while alkyl chains $\mathrm{C}_{4}$ or longer are required in aprotic ILs. ${ }^{27}$ IL nanostructure also changes if the alkyl chain is fluorinated or if multiple alkyl chains are employed. A rich variety of nanostructures have been reported ranging from smectic ${ }^{28-30}$ to sponge-like ${ }^{24}$ to clustered, ${ }^{23,31,32}$ and even tricontinuous when both hydrocarbon and fluorocarbon chains are employed. ${ }^{33}$

Amphiphilically nanostructured ILs are good solvents for polar $^{34-42}$ and apolar ${ }^{37,43-51}$ organic solutes, as well as inorganic materials, ${ }^{52-66}$ and some polymers. ${ }^{67-71}$ This capacity has opened new synthetic pathways and allowed otherwise difficult transformations to be performed. ${ }^{72}$ While it is relatively simple to determine what materials dissolve in an IL, it is much more difficult to experimentally determine how it is solvated, and how the solute in turn affects IL nanostructure. ${ }^{34,36,39,40,44,46}$ Understanding the nature of solvation, including the preferred orientation of solute and solvent atoms, is the key to understanding and optimising chemical and physical processes in ILs. Because of its importance for Li ion batteries, $\mathrm{Li}^{+}$solvation in ILs has been most extensively examined, ${ }^{59-66}$ although other ions such as $\mathrm{Cu}^{2+},{ }^{52} \mathrm{Zn}^{2+},{ }^{53} \mathrm{Mg}^{2+},{ }^{24,56} \mathrm{Na}^{+},{ }^{54,57,58} \mathrm{H}^{+73}$ and $\mathrm{H}_{3} \mathrm{O}^{+},{ }^{74}$ and amino acids ${ }^{75}$ have also attracted some attention. 
Neutron diffraction has been widely used to gain insights into the structure of ionic liquids and their solutions. ${ }^{76}$ In earlier work we used neutron diffraction and simulated fits ${ }^{55}$ to compare $\mathrm{Li}^{+}$solvation in ethylammonium nitrate (EAN) and ethanolammonium nitrate (EtAN). EAN has an amphiphilic, bicontinuous nanostructure with a sponge-like bulk morphology. $\mathrm{LiNO}_{3}$ is incorporated within the polar domains of EAN, which are relatively unperturbed by the addition, but ethyl chain packing in the apolar domains becomes frustrated leading to less well-defined nanostructure. In EtAN, the hydroxyl group disrupts the development of solvophobic nanostructure, so that only a weakly clustered morphology forms. Here however, the presence of $\mathrm{Li}^{+}$leads to - $\mathrm{OH}$ being expelled from the polar domains which transforms the clustered morphology ${ }^{23}$ into an amphiphilic sponge structure, reminiscent of that found in EAN.

In this work we probe the effect of $\mathrm{Cl}^{-}$on IL nanostructure using $15 \mathrm{~mol} \%$ solutions of propylammonium chloride (PACl) in propylammonium nitrate (PAN) and ethanolammonium chloride (EtACl) in ethanolammonium nitrate (EtAN). PAN has a sponge-like nanostructure in which segregation between the polar and apolar domains is even stronger than EAN, due to the longer propyl chains. Adding the chloride as the salt of the IL cation simplifies interpretation, in the same way as for our previous investigation of $\mathrm{Li}^{+}$by addition of $\mathrm{LiNO}_{3}{ }^{55}$

\section{Methods and materials}

A series of isotopically substituted $15 \mathrm{~mol} \%$ propylammonium chloride (PACl) in propylammonium nitrate (PAN) and $15 \mathrm{~mol} \%$ ethanolammonium chloride (EtACl) in ethanolammonium nitrate (EtAN) mixtures were prepared for neutron diffraction experiments; H-PACl:H-PAN, $\mathrm{d}_{3}-\mathrm{PACl}: \mathrm{d}_{3}-\mathrm{PAN}$ and $\mathrm{d}_{7}$-PACl: $\mathrm{d}_{7}-\mathrm{PAN}$ and H-EtACl:H-EtAN, $d_{4}$-EtACl: $d_{4}$-EtAN and $d_{\text {alk }}$-EtACl: $\mathrm{d}_{\text {alk }}$-EtAN. The structures and isotopic substitutions of these samples are given in Table 1.

H-PAN and H-EtAN were prepared via titration of nitric acid $\left(\mathrm{HNO}_{3}\right)($ Sigma-Aldrich, $68 \mathrm{w} / \mathrm{w} \%)$ into a chilled solution $\left(<5{ }^{\circ} \mathrm{C}\right)$ of the appropriate amine (propylamine (Sigma-Aldrich $98 \mathrm{wt} \%$ ) and ethanolamine (Sigma-Aldrich $98 \mathrm{wt} \%$ )) in distilled water as described previously. ${ }^{23}$ Excess water was removed firstly by rotary evaporation for several hours at $25{ }^{\circ} \mathrm{C}$ and then heating to $\sim 110{ }^{\circ} \mathrm{C}$ under $\mathrm{N}_{2}$ purge. The final water content of the ILS were determined to be $<0.1 \%$ by Karl-Fischer titration. $\mathrm{d}_{3}$-PAN and $\mathrm{d}_{4}$-EtAN were prepared by performing the acid-base reaction in deuterium oxide ( $\mathrm{D}_{2} \mathrm{O}$ (99\% Sigma Aldrich)). The prepared ILs were then washed with 3 molar equivalents of $\mathrm{D}_{2} \mathrm{O}$ and then dried by rotary evaporation for several hours at $25{ }^{\circ} \mathrm{C}$. This step was repeated twice before final drying by rotary evaporation for several hours at $25{ }^{\circ} \mathrm{C}$ and then heating to $\sim 110{ }^{\circ} \mathrm{C}$ under $\mathrm{N}_{2}$ purge. The final water content of the ILs was $<0.1 \%$ by Karl-Fischer titration. ${ }^{1} \mathrm{H}-\mathrm{NMR}$ experiments reveal that, on average, 2.5 out of 3 amino hydrogen atoms are replaced with deuterium. $d_{7}$-PAN and $d_{\text {alk-EtAN were synthesised by performing }}$ the acid-base reaction using $\mathrm{N}$-propyl- $\mathrm{d}_{7}$-amine (CDN isotopes) and ethanol-1,1,2,2- $\mathrm{d}_{4}$-amine (CDN isotopes) respectively. $\mathrm{d}_{10}$-PAN was prepared from $\mathrm{d}_{7}$-PAN by washing $\mathrm{d}_{7}$-PAN with 3 molar equivalents of $\mathrm{D}_{2} \mathrm{O}$ and followed by drying by rotary evaporation for several hours at $25{ }^{\circ} \mathrm{C}$, then repeating this step twice before final drying by rotary evaporation for several hours at $25{ }^{\circ} \mathrm{C}$ and then heating to $\sim 110{ }^{\circ} \mathrm{C}$ under $\mathrm{N}_{2}$ purge. The final water content of the IL was determined to be $<0.1 \%$ by Karl-Fischer titration. The chloride derivatives of the ILs were prepared as per the preparation of the nitrate IL contrasts but substituting $\mathrm{HNO}_{3}$ for $\mathrm{HCl}$ (Sigma Aldrich, 37\%).

Neutron scattering data were collected on all PAN:PACl and EtAN:EtACl samples (Table 1) using the SANDALS time of flight diffractometer at the ISIS pulsed neutron and muon source at the Rutherford Appleton Laboratory, UK. The instrument has a wavelength range of 0.05-4.95 $\AA$, and covers a $Q$ range of 0.1-50 $\AA^{-1}$. For the measurements, samples were contained in chemically inert, 'null scattering' $\mathrm{Ti}_{0.68} \mathrm{Zr}_{0.32}$ flat plate cells with internal geometries of $1 \times 35 \times 35 \mathrm{~mm}$, with a wall thickness of $1 \mathrm{~mm}$ sealed with PTFE O-rings. Samples were maintained at a temperature of $298 \mathrm{~K}$ using a recirculating heater (Julabo FP50) for the duration of the diffraction experiments. Measurements were made on each of the empty sample containers, the empty diffractometer, and a $3 \mathrm{~mm}$ thick vanadium standard sample to

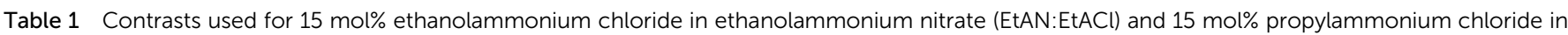

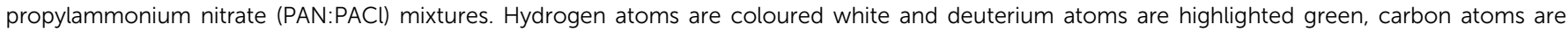
coloured grey, oxygen atoms are coloured red, nitrogen atoms are blue and chlorine atoms are green

H-EtAN + H-EtACl

$\mathrm{d}_{\mathrm{alk}}-\mathrm{EtAN}+\mathrm{d}_{\mathrm{alk}}-\mathrm{EtACl}$
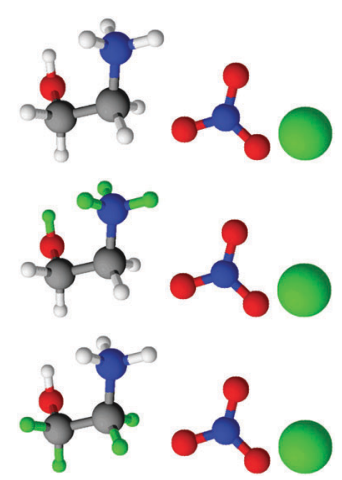

$\mathrm{d}_{3}-\mathrm{PAN}+\mathrm{d}_{3}-\mathrm{PACl}$

$\mathrm{H}-\mathrm{PAN}+\mathrm{H}-\mathrm{PACl}$
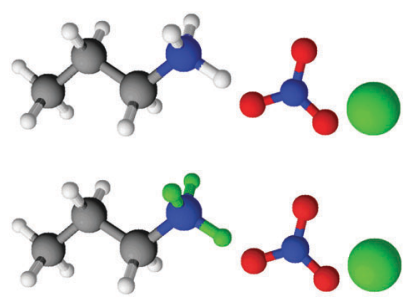

$\mathrm{d}_{7}-\mathrm{PAN}+\mathrm{d}_{7}-\mathrm{PACl}$

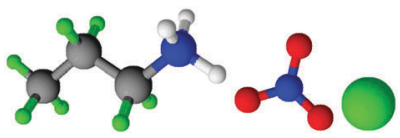




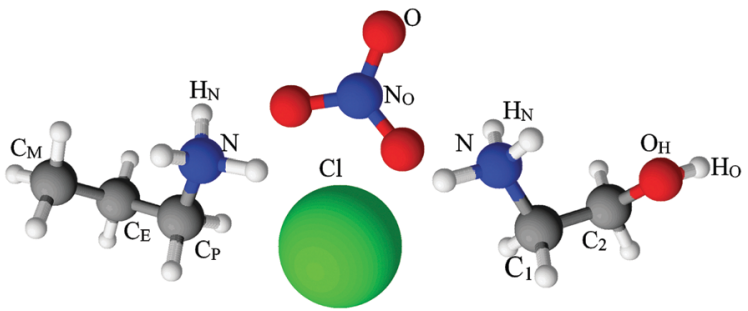

Fig. 1 Structures, and atom labels used, for the propylammonium (left), ethanolammonium (right), nitrate (top centre) and chloride (bottom centre) ions employed in the present study.

enable instrument calibration and data normalisation. The net run time for each measurement was $c a$. 8 hours. Reduction of raw scattering data was performed using GUDRUN as described in the ATLAS manual. ${ }^{77}$ Calibration, background subtraction and corrections for hydrogen inelasticity and single atom scattering were made to produce a differential scattering cross section for each sample. The normalised diffraction data were fitted using empirical potential structure refinement (EPSR) simulations. ${ }^{78,79}$ To guarantee internal consistency, the diffraction data of pure $\mathrm{PAN}^{13}$ and $\mathrm{EtAN}^{23}$ were re-reduced and re-fitted using the same version of GUDRUN and EPSR (see Fig. S1, ESI $\dagger$ ). The structures of EtAN and PAN are given in Fig. 1, along with the labels used to identify atoms, are shown. Previously published Lennard-Jones parameters were used as the reference potentials for the ethanolammonium nitrate, ${ }^{23}$ propylammonium nitrate ${ }^{13}$ and chloride ${ }^{80}$ ions within EPSR.

\section{Results and discussion}

Fig. 2 shows neutron diffraction patterns (open circles) obtained for 3 isotopomers of $15 \mathrm{~mol} \%$ propylammonium chloride in propylammonium nitrate (PAN:PACl) and $15 \mathrm{~mol} \%$ ethanolammonium chloride in ethanolammonium nitrate (EtAN:EtACl) mixtures. For each system, the 3 contrasts were simultaneously fit using the same simulation box. These fits are indicated by the solid lines in the Fig. 2. The fits agree well with the data, indicating the EPSR simulations faithfully capture the bulk atom-atom correlations that produce the measured diffraction patterns via a complex summation of (positive and negative) scattering contributions. ${ }^{25,32,81-83}$

Fig. 2A presents the data and fits for the PAN:PACl mixture. The $\mathrm{d}_{3}$ contrast for PAN:PACl mixture has a strong Bragg peak at $0.55 \AA^{-1}$, indicating a well-defined amphiphilic nanostructure. ${ }^{14}$ Fig. S2 in the ESI, $\uparrow$ provides an expansion of the low $Q$ data to show the peak more clearly, and the fit to the pure PAN data ${ }^{13}$ (dashed line) is reproduced for comparison. For the PAN:PACl mixture, the position of the strong peak at low $Q$ corresponds to a real space repeat spacing of $11.4 \AA$, which is slightly larger than twice the PAN ion pair diameter $(\sim 10.9 \AA)$. The pure PAN peak in the $\mathrm{d}_{3}$ contrast is slightly more intense and at lower $Q\left(0.53 \AA^{-1}\right)$ which corresponds to a larger repeat spacing of $11.9 \AA^{1 .} .^{3}$ Addition of $15 \mathrm{~mol} \%$ chloride causes the periodicity of the PAN nanostructure to decrease by $\sim 10 \%$.

Corresponding data for the EtAN:EtACl mixture are shown in Fig. 2B. Rather than the strong peak noted for PAN:PACl, the $\mathrm{d}_{4}$ contrast for pure $\mathrm{EtAN}^{23}$ and the EtAN:EtACl mixture both exhibit weak shoulders at low $Q$, indicating weaker nanostructure. The shoulder positions for pure EtAN and the EtAN:EtACl mixture are $0.70 \AA^{-1}$ and $0.98 \AA^{-1}$ respectively, corresponding to real space repeat spacings of $\sim 9.0 \AA^{55}$ and $\sim 6.4 \AA$. As in PAN, these are larger than the ion pair diameter of EtAN $(\sim 5.45 \AA)$, meaning the ions must associate into larger structures. The $30 \%$ decrease in the repeat spacing in EtAN compared to only $10 \%$ for PAN suggests that the nanostructure of EtAN is strongly affected by chloride addition.

Fig. $3 \mathrm{~A}$ and $4 \mathrm{~A}$ show snapshots of EPSR simulation boxes after convergence to the PAN:PACl and EtAN:EtACl diffraction data. $\mathrm{Cl}^{-}$anions are uniformly distributed throughout the mixture in both systems, with no obvious clustering or segregation. In Fig. $3 \mathrm{~B}$ and $4 \mathrm{~B}$ polar IL groups $\left(-\mathrm{NH}_{3}{ }^{+},-\mathrm{OH}\right.$ and $\left.\mathrm{NO}_{3}{ }^{-}\right)$are rendered red and cation alkyl groups $\left(-\mathrm{CH}_{2}-\right.$ and $\left.-\mathrm{CH}_{3}\right)$ grey to highlight the polar and nonpolar domains. For the PAN:PACl mixture in Fig. 3B the polar (red atoms) and apolar (grey atoms) domains are well segregated and extend through the bulk in a sponge structure similar to pure PAN. ${ }^{13}$ Compared to PAN:PACl, in the EtAN:EtACl mixture the polar domain volume fraction is
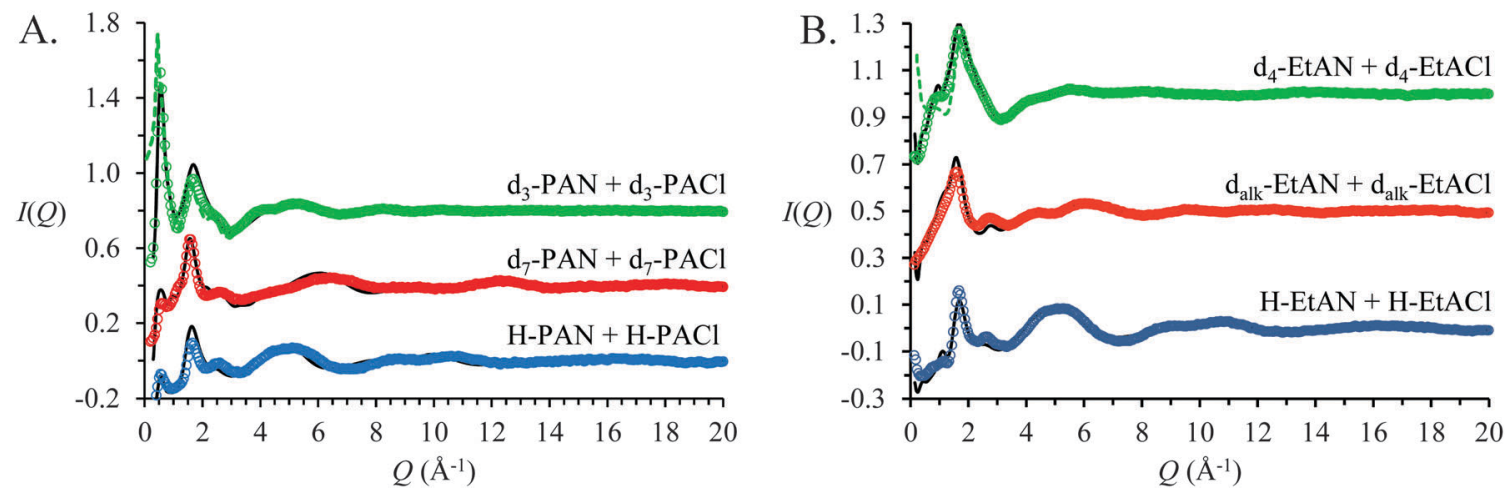

Fig. 2 SANDALS neutron diffraction data and EPSR derived fits for 15 mol\% propylammonium chloride (PACl) in propylammonium nitrate (PAN) (A) and (B) $15 \mathrm{~mol} \%$ ethanolammonium chloride (EtACl) in ethanolammonium nitrate (EtAN). Coloured dots show the experimentally measured $/(Q)$ and the black lines the EPSR fits. The corresponding diffraction patterns for pure $d_{3}-$ PAN $^{13}$ and $d_{4}-E_{t A N}{ }^{23}$ are included as dotted lines. Data are offset for clarity. 
A.

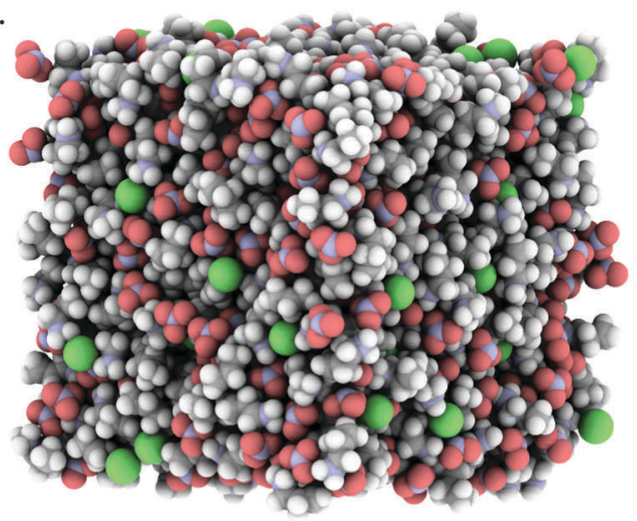

B.

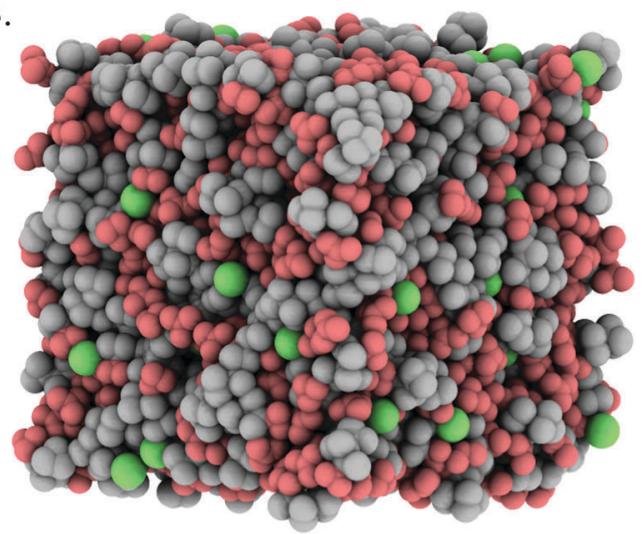

Fig. 3 Snapshot of fitted bulk structure for 15 mol\% propylammonium chloride (PACl) in propylammonium nitrate (PAN) equilibrated at $298 \mathrm{~K}$. From left to right (A) all atoms, 500 $\mathrm{PA}^{+}, 425 \mathrm{NO}_{3}^{-}, 75 \mathrm{Cl}^{-}, \mathrm{H}$ atoms are shown in white, $\mathrm{C}$ atoms in grey, $\mathrm{N}$ atoms in blue, $\mathrm{O}$ atoms in red and $\mathrm{Cl}$ in green; (B) polar IL atoms (ammonium and nitrate) are coloured red, apolar IL atoms (alkyl groups) are grey and $\mathrm{Cl}$ atoms are green.
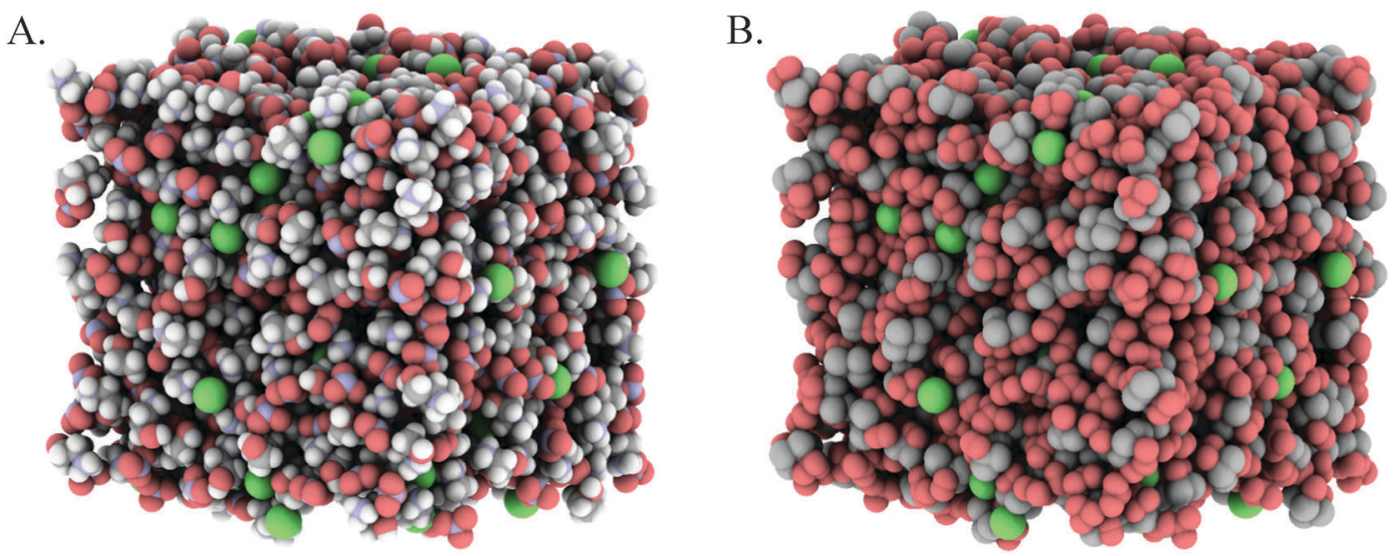

Fig. 4 Snapshot of fitted bulk structure for $15 \mathrm{~mol} \%$ ethanolammonium chloride (EtACl) in ethanolammonium nitrate (EtAN) equilibrated at $298 \mathrm{~K}$. From left to right (A) all atoms, 500EtA $, 425 \mathrm{NO}_{3}^{-}, 75 \mathrm{Cl}^{-}, \mathrm{H}$ atoms are shown in white, $\mathrm{C}$ atoms in grey, $\mathrm{N}$ atoms in blue, $\mathrm{O}$ atoms in red and $\mathrm{Cl}$ in green; (B) polar IL atoms (ammonium, hydroxyl and nitrate) are coloured red, apolar IL atoms (alkyl groups) are grey and chloride atoms are green.

increased because the cation alkyl chain is 1 methylene group shorter and the terminal alcohol group is shaded red in accordance with its polarity, i.e. the cation alcohol group is part of the polar domain. Segregation is weak in the EtAN:EtACl mixture; extended apolar domains are not present, and the polar domains are less well defined than for the PAN:PACl mixture.

Inspection of the box snapshots in Fig. 3B and 4B reveals that the green chloride ions tend to interact with red polar atoms, consistent with the chloride being preferentially solvated by polar groups, in both the PAN:PACl and EtAN:EtACl mixtures. Note that this does not mean that the chloride is solvated exclusively in the charged domain, but at any instant is much less likely to be found in an apolar environment. This is clear even from the box snapshots, where some chloride ions are in contact with more apolar groups than polar groups.

Partial radial distribution functions, $g_{i j}(r)$, spatial density function (SDF) plots and the associated coordination numbers reveal the extent to which chloride-cation interactions are favoured. To simplify discussion, the data for the PAN:PACl mixture is examined first, followed by that for EtAN:EtACl mixture.
Fig. 5 shows key $g_{i j}(r)$ functions for the PAN:PACl mixture (solid coloured lines) with the corresponding functions for pure PAN included for comparison (black dashed lines). While some correlation functions in pure PAN and the PAN:PACl mixture are quite similar, in other cases there are marked differences. The coordination numbers derived from the $g_{i j}(r)$ functions in Fig. 5 are given in Table 2 for PAN and its chloride solution.

The strongest forces between IL ions are electrostatic attractions between cations and anions. In the PAN:PACl mixture the ammonium cation is electrostatically attracted to both the nitrate and chloride anions. The $g_{i j}(r)$ functions for these interactions are shown in Fig. 5A $(\mathrm{Cl} \cdots \mathrm{N})$ and Fig. $5 \mathrm{~B}\left(\mathrm{~N}_{\mathrm{O}} \cdots \mathrm{N}\right)$; the $\mathrm{N}$ atom defines the centre of mass of the cation ammonium charge group, and the $\mathrm{N}_{\mathrm{O}}$ atom the centre of mass of the nitrate. The $\mathrm{Cl} \cdots \mathrm{N}$ correlation function has a sharp, intense peak, while the peak in the $\mathrm{N}_{\mathrm{O}} \cdots \mathrm{N}$ data is weaker and broader. The maximum in the peak for the $\mathrm{Cl} \cdots \mathrm{N}$ is 5 (meaning that at this distance the probability of finding a chloride ion is five times greater than the bulk average) while the peak maximum for $\mathrm{N}_{\mathrm{O}} \cdots \mathrm{N}$ is 3.5 . These differences can be attributed to the different structures 

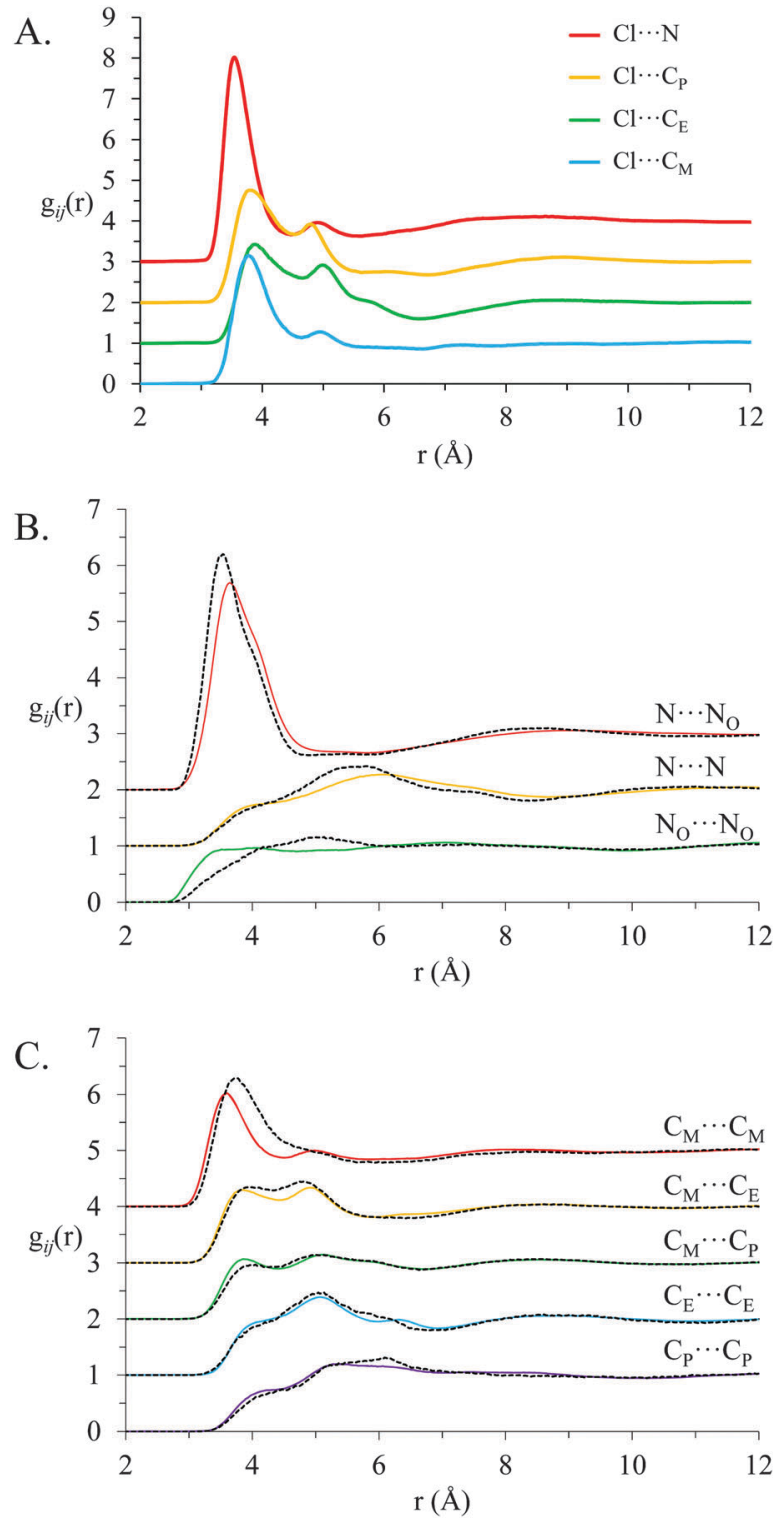

Fig. 5 Key $g_{i j}(r)$ functions for (A) chloride-PAN charge group correlations; (B) PAN...PAN charge groups correlations and (C) PAN...PAN alkyl groups correlations in a $15 \mathrm{~mol} \% \mathrm{PAN}: \mathrm{PACl}$ mixture. Solid lines indicate data for the present PAN:PACl mixture and dashed lines show the corresponding functions for pure PAN. Data sets are offset for clarity.

and hardness (charge localisation) of chloride and nitrate ions. The spherical chloride ion can approach ammonium groups unimpeded and the charge is centred on a single atom. On the other hand, the nitrate anion is larger and the charge is distributed by resonance. As a result, the position of the nitrate ion relative to the ammonium charge centre is not as well defined as for chloride.

These differences are also reflected in the coordination numbers for ammonium $\mathrm{N}$ atom around the chloride anions $(\mathrm{Cl}-\mathrm{N})$, the ammonium $\mathrm{N}$ around the nitrate $\mathrm{N}\left(\mathrm{N}_{\mathrm{O}}-\mathrm{N}\right)$, and nitrate $\mathrm{N}$ around ammonium $\mathrm{N}\left(\mathrm{N}-\mathrm{N}_{\mathrm{O}}\right)$ in the mixture. The first coordination shell around the chloride anion (extending to $4.5 \AA$ ) is dominated by the cation ammonium group. The $\mathrm{Cl}-\mathrm{N}$ coordination number is 2.92 which means that on average each chloride has 2.92 ammonium nearest neighbours, and the Cl- $\mathrm{H}_{\mathrm{N}}$ coordination number over the same distance is 6.52. That is, each chloride is surrounded by $\sim 3$ cation charge centres via two ammonium protons. Cation alkyl tails are necessarily present in the chloride coordination shell a due to their bonding to the ammonium group, but coordination numbers are relatively small. The peak in $g_{i j}(r)$ between chloride and the terminal methyl of the propylammonium cation $\left(\mathrm{Cl} \cdots \mathrm{C}_{\mathrm{M}}\right)$ is more intense than for the $\mathrm{Cl} \cdots \mathrm{C}_{\mathrm{E}}$ and $\mathrm{Cl} \cdots \mathrm{C}_{\mathrm{P}}$ functions. The reason for this unusual feature is discussed below. The $\mathrm{N}_{\mathrm{O}}-\mathrm{N}$ coordination number (3.40) is higher than the $\mathrm{Cl}-\mathrm{N}$ coordination number because the larger nitrate allows more cations to approach. The $\mathrm{N}-\mathrm{N}_{\mathrm{O}}$ coordination number is 2.89 , which is smaller than the $\mathrm{N}_{\mathrm{O}}-\mathrm{N}$ coordination number because the cation charge group also coordinates with chloride.

The peak in the $\mathrm{N}_{\mathrm{O}} \cdots \mathrm{N}$ correlation function is smaller and shifted to slightly larger separations in the PAN:PACl mixture than in pure PAN. These results are consistent with the chloride being strongly and closely associated with the ammonium charged group, and that this changes the polar domain structure sufficiently that nitrates are effectively displaced further from the ammonium centre. As a result of stronger $\mathrm{Cl}-\mathrm{N}$ interactions, the $\mathrm{N}-\mathrm{N}_{\mathrm{O}}$ coordination number in the mixture (2.89) is lower than in pure PAN (3.66) by more than expected from the molar composition of the mixture. There is a corresponding decrease in the $\mathrm{N}_{\mathrm{O}}-\mathrm{C}_{\mathrm{P}}$ coordination number for the same reason.

The $\mathrm{N} \cdots \mathrm{N}$ and $\mathrm{N}_{\mathrm{O}} \cdots \mathrm{N}_{\mathrm{O}}$ correlation functions and coordination numbers are similar in the mixture and pure PAN, as expected for like charges. Similarly, interactions between chloride and nitrate are repulsive, so the $\mathrm{Cl}-\mathrm{N}_{\mathrm{O}}$ coordination number is also small (0.47).

The $g_{i j}(r)$ functions for alkyl chain atoms $\left(\mathrm{C}_{\mathrm{x}} \cdots \mathrm{C}_{\mathrm{x}}\right)$ for pure PAN and the PAN:PACl mixture are given in Fig. 5C, and the corresponding coordination numbers in Table 2 . In both systems pronounced peaks are evident at separations between 3 and $5.5 \AA$ A, indicating alkyl chains are associated. ${ }^{13}$ For PAN:PACl this is consistent with the presence of apolar domains and the sponge nanostructure in the simulation snapshot (Fig. 3).

The $\mathrm{C}_{\mathrm{E}} \cdots \mathrm{C}_{\mathrm{x}}$ and $\mathrm{C}_{\mathrm{P}} \cdots \mathrm{C}_{\mathrm{x}}$ correlation functions and coordination numbers are generally similar for pure PAN and the PAN:PACl mixture. However, correlation functions and coordination numbers involving the terminal carbon $\left(\mathrm{C}_{\mathrm{M}}\right)$ differ markedly between the mixture and pure PAN. Comparison of the $\mathrm{C}_{\mathrm{M}} \cdots \mathrm{C}_{\mathrm{M}}$ correlation functions in the mixture and pure PAN reveals that the position of the maximum is slightly reduced from $3.75 \AA$ in pure PAN to $3.57 \AA$ in the mixture, but the peak intensity is substantially lower. Accordingly, the $C_{M} \cdots C_{M}$ coordination number in the mixture is 1.86 compared to 2.16 in pure PAN. While $\mathrm{C}_{\mathbf{M}} \cdots \mathrm{C}_{\mathbf{M}}$ interactions are diminished, the coordination numbers for $\mathrm{C}_{M}-\mathrm{N}$ increase by $73 \%$, however the $\mathrm{C}_{\mathrm{M}}-\mathrm{N}_{\mathrm{O}}$ coordination number is essentially unchanged in the mixture compared to pure PAN, and there are 0.41 chloride ions coordinated with each cation methyl group. These results reveal that the terminal carbon of the cation alkyl chain has significantly more interactions with the charged domain in the 
Table 2 Key coordination numbers for pure PAN and a 15 mol\% PAN:PACl mixture derived from the EPSR model interionic partial radial $g_{i j}(r)$ data. The cut-off distances $(r)$ used $(\AA)$ are indicated in parentheses next to each coordination number. The coordination numbers are defined with the first atom at the centre with the second atom coordinating it

\begin{tabular}{lllll}
\hline & & Pure PAN & PAN:PACl & $r(\beta) / \mathrm{A}$ \\
\hline Nitrate-nitrate & $\mathrm{N}_{\mathrm{O}}-\mathrm{N}_{\mathrm{O}}$ & 0.72 & 0.80 & $(4.0)$ \\
Nitrate-cation & & & & \\
& $\mathrm{N}_{\mathrm{O}}-\mathrm{C}_{\mathrm{M}}$ & 1.45 & 1.64 & $(4.5)$ \\
& $\mathrm{C}_{\mathrm{M}}-\mathrm{N}_{\mathrm{O}}$ & 1.45 & 1.39 & $(4.5)$ \\
& $\mathrm{N}_{\mathrm{O}}-\mathrm{C}_{\mathrm{P}}$ & 2.51 & 2.24 & $(4.5)$ \\
& $\mathrm{N}-\mathrm{N}_{\mathrm{O}}$ & 3.66 & 2.89 & $(4.4)$ \\
& $\mathrm{N}_{\mathrm{O}}-\mathrm{N}$ & 3.66 & 3.40 & $(4.4)$ \\
Cation-cation & & & & \\
& $\mathrm{C}_{\mathrm{M}}-\mathrm{C}_{\mathrm{M}}$ & 2.16 & 1.86 & $(4.5)$ \\
& $\mathrm{C}_{\mathrm{M}}-\mathrm{C}_{\mathrm{E}}$ & 1.51 & 1.48 & $(4.5)$ \\
& $\mathrm{C}_{\mathrm{M}}-\mathrm{C}_{\mathrm{P}}$ & 1.09 & 1.19 & $(4.5)$ \\
& $\mathrm{C}_{\mathrm{M}}-\mathrm{N}$ & 0.62 & 1.07 & $(4.5)$ \\
& $\mathrm{C}_{\mathrm{P}}-\mathrm{N}$ & 0.68 & 0.70 & $(4.5)$ \\
& $\mathrm{N}^{-\mathrm{N}}$ & 0.68 & 0.81 & $(4.4)$ \\
& $\mathrm{C}_{\mathrm{E}}-\mathrm{C}_{\mathrm{E}}$ & 2.08 & 2.07 & $(5.0)$ \\
& $\mathrm{C}_{\mathrm{P}}-\mathrm{C}_{\mathrm{P}}$ & 0.73 & 0.85 & $(4.6)$ \\
& & & & \\
& & - & 2.92 & $(4.5)$ \\
Chloride-cation & $\mathrm{Cl}-\mathrm{N}$ & - & 0.44 & $(4.5)$ \\
& $\mathrm{N}-\mathrm{Cl}$ & - & 6.52 & $(4.5)$ \\
& $\mathrm{Cl}-\mathrm{H}_{\mathrm{N}}$ & - & 0.41 & $(4.5)$ \\
& $\mathrm{C}_{\mathrm{M}}-\mathrm{Cl}$ & - & & \\
& & & 0.47 &
\end{tabular}

mixture than in pure PAN. This could mean that cation alkyl chains are interdigitated and traverse the apolar domain. However, if this conformation was present the $\mathrm{C}_{\mathrm{M}} \cdots \mathrm{C}_{\mathrm{P}}$ coordination number should also be strongly enhanced, and the real space repeat spacing decreased, yet both change by only $\sim 10 \%$ on chloride addition. Rather, packing considerations must dictate that a cation alkyl chain is rotated towards the charged domain. This accounts for the increased $\mathrm{Cl} \cdots \mathrm{C}_{\mathrm{M}} g_{i j}(r)$ intensity relative to the $\mathrm{Cl} \cdots \mathrm{C}_{\mathrm{E}}$ and $\mathrm{Cl} \cdots \mathrm{C}_{\mathrm{P}}$ functions (Fig. $5 \mathrm{~A}$ ).

In pure PAN, alkyl chains preferentially pack in the apolar domain with "end-to-end" organisation. ${ }^{24}$ This produces: (1) a strong $\mathrm{C}_{\mathbf{M}} \cdots \mathrm{C}_{\mathbf{M}} g_{i j}(r)$ peak, (2) for the $\mathrm{C}_{\mathrm{E}}-\mathrm{C}_{\mathbf{M}} \cdots \mathrm{C}_{\mathrm{M}}$ triplet (where the $\mathrm{C}_{\mathrm{E}}-\mathrm{C}_{\mathrm{M}}$ are carbon atoms on the same ion and ${ }^{-C_{M}}$ represents their correlation with the methyl carbon of a different cation) $19 \%$ of all cations are within $\pm 15^{\circ}$ of $180^{\circ}$, and (3) $\sim 61 \%$ of the propylammonium cations have trans (anti) conformation. In the PAN:PACl mixture the $\mathrm{C}_{\mathbf{M}} \cdot \mathrm{C}_{\mathbf{M}} g_{i j}(r)$ peak has a reduced intensity, only $16 \%$ of all cation pack end-to-end, and only $43 \%$ of cations are in the trans conformation. These changes lead to less regular alkyl chain packing in apolar domains, due rotation about the $\mathrm{C}_{\mathrm{P}}-\mathrm{C}_{\mathrm{E}}$ bond which leads to a greater proportion of cation methyl groups contacting the polar domain.

Spatial density function (SDF) plots are three dimensional reconstructions of $g_{i j}(r)$ data and reveal spatial orientations of atom pairs. SDF plots for key correlations around the cation ammonium, cation alkyl chains and nitrate anions are presented in Fig. 6. To emphasise that the cation can freely rotate about the $\mathrm{C}_{\mathrm{E}}-\mathrm{C}_{\mathrm{P}}$ bond, and that the SDF surfaces represent data for all conformations in the converged simulation, the propylammonium cation is shown in the trans conformation in Fig. $6 \mathrm{D}$ and the gauche conformation in Fig. $6 \mathrm{~A}-\mathrm{C}, \mathrm{E}$ and $\mathrm{F}$.
The arrows indicate a freely rotating molecular fragment. The SDF plots in Fig. 6A-C show that nitrate and chloride anions, and cation ammonium groups, preferentially pack around cation ammonium groups and are excluded from the region around the alkyl chain. This is consistent with segregation of charge and alkyl groups into separate domains.

The $g_{i j}(r)$ functions in Fig. 5A show that ammonium charge centres associate more closely with chloride than nitrate ions, attributed to stronger interactions with small, hard chloride ion. As electrostatic forces dominate other interactions between ions, and chloride-ammonium interactions are the strongest in the mixture, packing around the chloride will thus maximise interactions with ammonium groups. Given that the $\mathrm{Cl}-\mathrm{N}$ coordination number is $\sim 3$ (2.9), a trigonal planar configuration would allow cation charge centres to approach the chloride most closely while minimising steric interactions between ammonium hydrogen atoms. However, the angle distribution for $\mathrm{N} \cdots \mathrm{Cl} \cdots \mathrm{N}$ atom triplets (Fig. S3, ESI $\dagger$ ) reveals a broad distribution centred around $\sim 100^{\circ}$, as opposed to $120^{\circ}$ which would be expected for perfect trigonal planar symmetry. Thus, while trigonal planar symmetry might be electrostatically preferred, it is disrupted by the requirement to maintain segregation of polar and apolar groups. This is borne out in the Cl@N SDF plot in Fig. 6A, where the largest chloride lobe extends from above the cation charge centre towards the $\mathrm{C}_{\mathrm{E}}-\mathrm{C}_{\mathrm{P}}$ axis. This arrangement facilitates close approach of the cation and chloride while enabling the cation alkyl chain to orient towards the apolar phase. The three smaller chloride lobes around the equator of the ammonium group could indicate $\mathrm{N}-\mathrm{H} \cdots \mathrm{Cl}$ hydrogen bonds.

The $\mathrm{N}_{\mathrm{O}} @ \mathrm{~N}$ plot (Fig. 6B) shows the distribution of nitrate anions around ammonium centres mimics that of the chloride anions, with one large lobe above the $\mathrm{N}$ atom (in the $\mathrm{C}_{\mathrm{P}}-\mathrm{N}$ axis) extending backwards and two smaller lobes to either side of the ammonium group. This is starkly different to the $\mathrm{N}_{\mathrm{O}} @ \mathrm{~N}$ SDF function in pure PAN, which has three density lobes symmetrically distributed around the ammonium group due to equal sharing of cations between anions, satisfying electrostatic and $\mathrm{H}$-bonding interactions, ${ }^{13}$ and reflects changes in the polar domain structure seen in the corresponding $\mathrm{N}-\mathrm{N}_{\mathrm{O}} g_{i j}(r)$ induced by addition of chloride ion (Fig. 5A). By contrast, the $\mathrm{N} @ \mathrm{~N}_{\mathrm{O}}$ and $\mathrm{N}_{\mathrm{O}} @ \mathrm{~N}_{\mathrm{O}} \mathrm{SDF}$ plots for the mixture in Fig. 6H and I are remarkably similar to those in pure PAN, ${ }^{24}$ and Fig. $6 \mathrm{~J}$ shows that chloride ions are also arranged about nitrate in a similar way in the mixture. Thus, while the presence of chloride significantly changes the way cations pack around anions, anion around anion arrangements are similar in pure PAN and the mixture, regardless of whether the anion is nitrate or chloride; anions stack to minimise electrostatic repulsions.

The N@N SDF distribution for the mixture is also different to that for pure PAN, cf. (Fig. 6C). In the PAN:PACl mixture a single broad density lobe wraps around one side of the cation $\mathrm{N}$ atom, whereas in pure PAN, the N@N SDF plot has 4 lobes, one above the $\mathrm{N}$ atom (in the $\mathrm{C}_{\mathrm{P}}-\mathrm{N}$ axis) and 3 symmetrically distributed around the equator of the ammonium group. The altered N@N SDF function for the mixture is a result of strong interactions between the ammonium and chloride templating 
A.
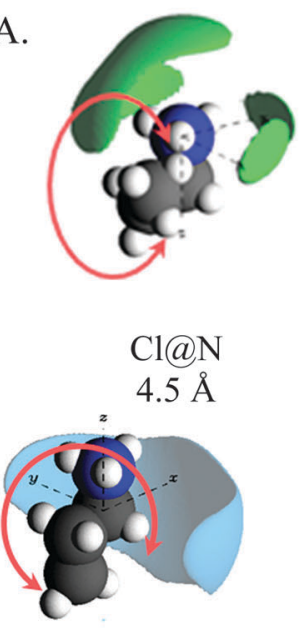

$\mathrm{C}_{\mathrm{P}} @ \mathrm{C}_{\mathrm{P}}$ $4.5 \AA$

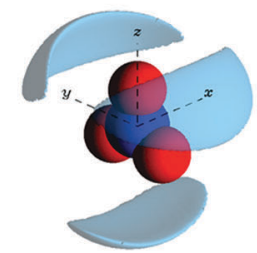

$\mathrm{N} @ \mathrm{~N}_{\mathrm{O}}$ $4.5 \AA$
B.

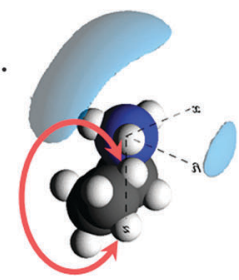

E.

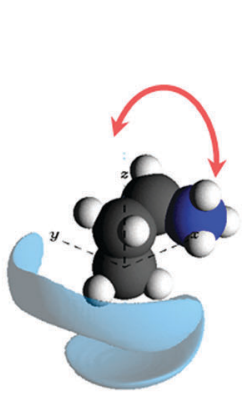

$\mathrm{C}_{\mathrm{M}} @ \mathrm{C}_{\mathrm{M}}$

$4.5 \AA$

$$
\mathrm{N}_{\mathrm{O}} @ \mathrm{~N}
$$

$4.5 \AA$

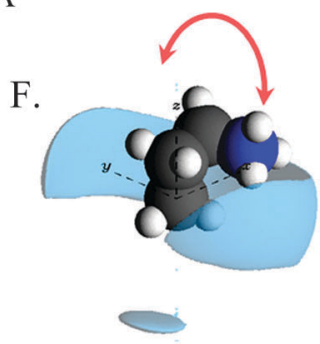

$\mathrm{N}_{\mathrm{O}} @ \mathrm{C}_{\mathrm{M}}$

$4.5 \AA$

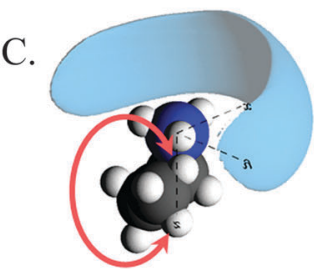

$\mathrm{N} @ \mathrm{~N}$
$4.5 \AA$

G.

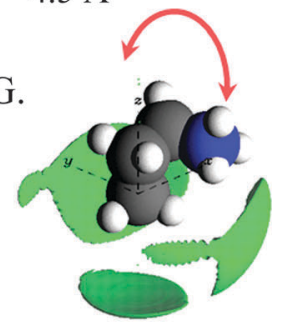

$\mathrm{Cl} @ \mathrm{C}_{\mathrm{M}}$ $4.5 \AA$

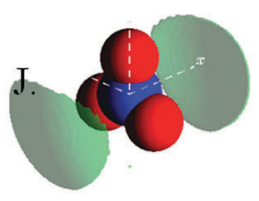

$\mathrm{Cl} @ \mathrm{~N}_{\mathrm{O}}$

Fig. 6 Spherical density function (SDF) plots for (A) $C l \cdots N$, (B) $N_{O} \cdots N,(C) N \cdots N$, (D) $C_{P} \cdots C_{P},(E) C_{M} \cdots C_{M},(F) N_{O} \cdots C_{M},(G) C l \cdots C_{M}$, for (H) $N_{O} \cdots N$ and (I) $\mathrm{N}_{\mathrm{O}} \cdots \mathrm{N}_{\mathrm{O}}$ and (J) $\mathrm{Cl} \cdots \mathrm{N}_{\mathrm{O}}$ correlations in a $15 \mathrm{~mol} \% \mathrm{PAN}$ :PACl mixture. All plots show the $20 \%$ isosurface for the distribution. Cut-off radii used for each plot are given below the plot. Plots showing atomic distributions about a central cation depict the cation in its preferred gauche conformer, except for the $C_{P} @ C_{P}$ distribution which depicts the trans conformer. It should be noted that the cation can freely rotate about the $C_{E}-C_{P}$ bond as indicated by the red arrows, meaning that a distribution of conformers exists in the liquid.

coordination in neighbouring charge groups in addition to the increased proportion cations adopting the gauche conformation which frustrates cation-cation packing compared to pure PAN. The $\mathrm{N}-\mathrm{Cl}$ coordination number of 0.43 (Table 2) means that almost half $(43 \%)$ of all cations in the system are associated with a chloride at any moment. This explains how a chloride ion concentration of just $15 \%$ alters cation packing globally throughout the mixture.

The $g_{i j}(r)$ functions for interactions between cation alkyl chain carbons revealed a marked change for the $\mathrm{C}_{\mathrm{M}} \cdots \mathrm{C}_{\mathrm{M}}$ correlations for the mixture compared to pure PAN, but other correlations were largely unchanged. However, the SDF plots for $\mathrm{C}_{\mathrm{P}} @ \mathrm{C}_{\mathrm{P}}$ and $\mathrm{C}_{\mathrm{M}} @ \mathrm{C}_{\mathrm{M}}$ in the PAN:PACl mixture (Fig. 6D and E) are different to those for PAN, meaning that alkyl chain packing in the apolar phase is more strongly affected by the presence of chloride than the $g_{i j}(r)$ functions suggest. In pure PAN, the $\mathrm{C}_{M} @ \mathrm{C}_{M}$ exhibits a single, symmetrical "claw-shaped" lobe that wraps around the cation $\mathrm{C}_{\mathrm{M}}$ atom, ${ }^{24}$ consistent with cations arranged in a bilayer within the sponge nanostructure.
In the mixture, the $\mathrm{C}_{\mathrm{M}} @ \mathrm{C}_{\mathrm{M}}$ distribution has two density lobes. One lobe is located beneath the terminal carbon in the direction of the $\mathrm{C}_{\mathrm{M}}-\mathrm{C}_{\mathrm{E}}$ axis, and the second lobe wraps behind the $\mathrm{C}_{\mathrm{M}}-\mathrm{C}_{\mathrm{E}}$ axis. This difference is a consequence of the gauche:trans changing from $40: 60$ in pure PAN to $60: 40$ in the mixture, cf. Fig. S4 (ESI $\dagger$ ). The change in the $\mathrm{C}_{\mathrm{M}} @ \mathrm{C}_{\mathrm{M}}$ plot and the conformer distribution from pure PAN to the mixture are a consequence of the quasi trigonal pyramidal packing of propylammonium cations around chloride (which templates similar packing around nitrate). In this splayed configuration there is insufficient space for all three cation terminal carbons in the volume beneath the chloride atom in the apolar phase, which necessitates more cations adopting the gauche conformation, and a significant number of $\mathrm{C}_{M}$ atoms contact the polar phase. This is borne out by the $\mathrm{N}_{\mathrm{O}} @ \mathrm{C}_{\mathrm{M}}$ and $\mathrm{Cl}_{\mathrm{O}} \mathrm{C}_{\mathrm{M}}$ SDF plots which show significant probability density below and around the terminal cation.

Fig. 7 shows key $g_{i j}(r)$ functions for the EtAN:EtACl mixture (solid coloured lines) and the corresponding coordination 

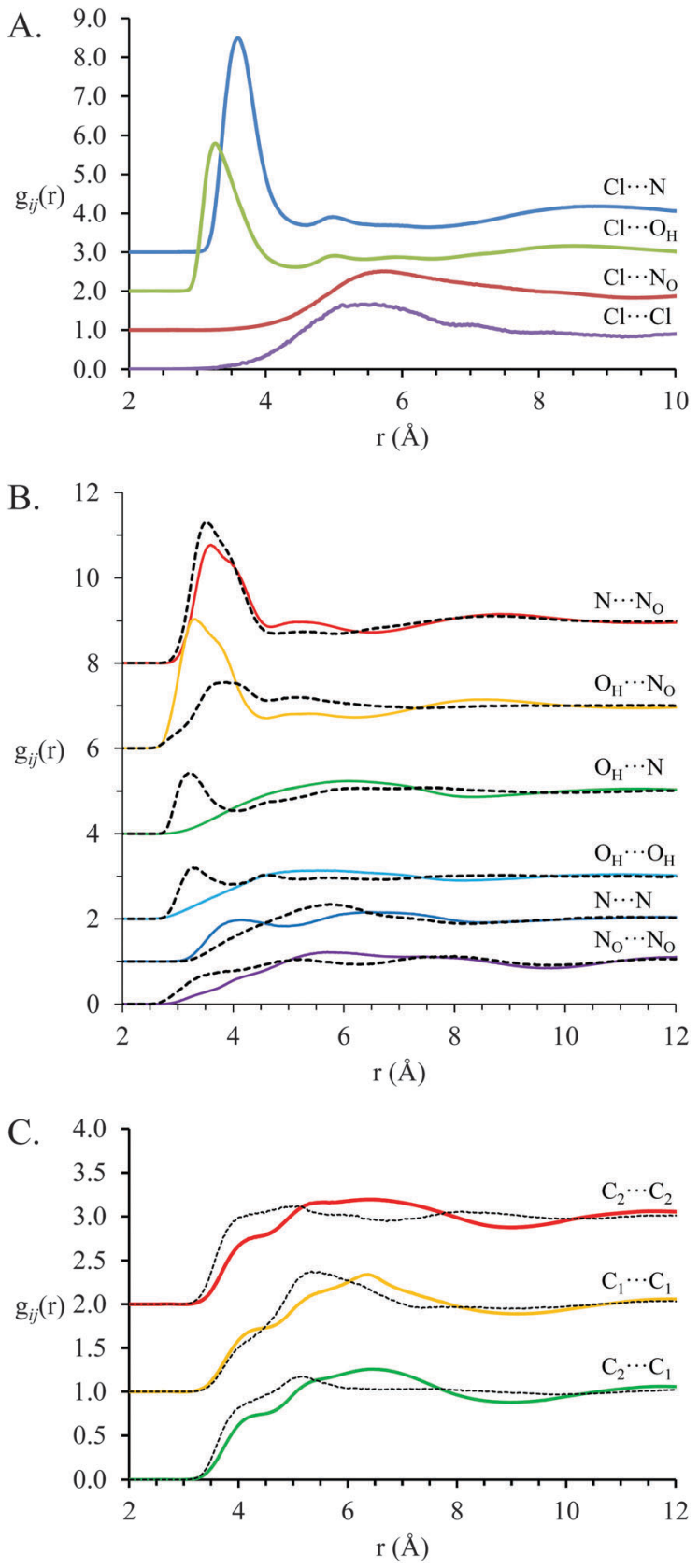

Fig. 7 Key $g_{i j}(r)$ functions for (A) Cl...EtAN correlations, (B) EtAN ...EtAN correlations and (C) $\mathrm{EtA}^{+}$carbon-carbon correlations in a $15 \mathrm{~mol} \%$ EtAN:EtACl mixture. Solid lines indicate data for the present EtAN:EtACl mixture and dashed lines represent the corresponding $g_{i j}(r)$ functions for pure EtAN. Data sets are offset for clarity.

numbers are presented in Table 3. Correlations involving chloride anions are presented in Fig. 7A, between ethanolammonium cations and nitrate anions correlations in Fig. 7B and correlations between ethanolammonium carbon atoms in Fig. 7C. $g_{i j}(r)$ functions for pure EtAN are included for comparison (black dashed lines) where possible. Unlike the PAN:PACl mixture, all correlation functions in the EtAN:EtACl mixture differ markedly from those in pure EtAN, indicating the native clustered nanostructure of EtAN is more strongly
Table 3 Key coordination numbers for pure EtAN and a 15 mol\% EtAN:EtACl mixture derived from the EPSR model interionic partial radial $g_{i j}(r)$ data. The cut-off distances $(\beta)$ used $(\AA)$ to calculate both sets of coordination numbers are indicated in parentheses. The coordination numbers are defined with the first atom at the centre with the second atom coordinating it

\begin{tabular}{|c|c|c|c|c|}
\hline & & Pure EtAN & EtAN:EtACl & $r(\beta) / \AA$ \\
\hline \multirow[t]{2}{*}{ Nitrate-nitrate } & $\mathrm{N}_{\mathrm{O}}-\mathrm{N}_{\mathrm{O}}$ & 0.98 & 0.47 & (4.3) \\
\hline & $\mathrm{N}_{\mathrm{O}}-\mathrm{O}$ & 2.15 & 1.06 & $(4.0)$ \\
\hline \multirow[t]{9}{*}{ Cation-cation } & $\mathrm{C}_{2}-\mathrm{C}_{2}$ & 1.20 & 0.72 & $(4.5)$ \\
\hline & $\mathrm{C}_{2}-\mathrm{C}_{1}$ & 0.99 & 0.65 & (4.5) \\
\hline & $\mathrm{C}_{2}-\mathrm{N}$ & 1.14 & 1.39 & (4.5) \\
\hline & $\mathrm{C}_{2}-\mathrm{O}_{\mathrm{H}}$ & 0.80 & 0.28 & $(4.0)$ \\
\hline & $\mathrm{C}_{1}-\mathrm{C}_{1}$ & 2.89 & 2.28 & (5.5) \\
\hline & $\mathrm{N}-\mathrm{N}$ & 0.98 & 1.11 & (4.5) \\
\hline & $\mathrm{O}_{\mathrm{H}^{-}}-\mathrm{O}_{\mathrm{H}}$ & 0.97 & 0.40 & $(4.0)$ \\
\hline & $\mathrm{H}_{\mathrm{O}}-\mathrm{O}_{\mathrm{H}}$ & 0.23 & 0.06 & $(3.0)$ \\
\hline & $\mathrm{H}_{\mathrm{N}}-\mathrm{O}_{\mathrm{H}}$ & 0.33 & 0.25 & $(3.0)$ \\
\hline \multirow[t]{7}{*}{ Nitrate-cation } & $\mathrm{N}_{\mathrm{O}}-\mathrm{N}$ & 3.45 & 2.80 & $(4.5)$ \\
\hline & $\mathrm{N}-\mathrm{N}_{\mathrm{O}}$ & 3.45 & 2.38 & (4.5) \\
\hline & $\mathrm{N}_{\mathrm{O}}-\mathrm{C}_{1}$ & 2.98 & 2.27 & $(4.5)$ \\
\hline & $\mathrm{N}_{\mathrm{O}}-\mathrm{C}_{2}$ & 2.37 & 2.55 & $(4.5)$ \\
\hline & $\mathrm{N}_{\mathrm{O}}-\mathrm{O}_{\mathrm{H}}$ & 2.17 & 3.05 & $(4.5)$ \\
\hline & $\mathrm{H}_{\mathrm{N}}-\mathrm{O}$ & 2.29 & 1.34 & $(3.0)$ \\
\hline & $\mathrm{H}_{\mathrm{O}}-\mathrm{O}$ & 1.80 & 2.04 & $(3.0)$ \\
\hline \multirow[t]{6}{*}{ Chloride-cation } & $\mathrm{Cl}-\mathrm{N}$ & & 3.53 & $(4.5)$ \\
\hline & $\mathrm{N}-\mathrm{Cl}$ & & 0.53 & (4.5) \\
\hline & $\mathrm{Cl}-\mathrm{O}_{\mathrm{H}}$ & & 2.44 & $(4.5)$ \\
\hline & $\mathrm{O}_{\mathrm{H}}-\mathrm{Cl}$ & & 0.32 & (4.5) \\
\hline & $\mathrm{Cl}-\mathrm{H}_{\mathrm{O}}$ & & 2.33 & (4.5) \\
\hline & $\mathrm{Cl}-\mathrm{H}_{\mathrm{N}}$ & & 2.28 & (3.0) \\
\hline Chloride-nitrate & $\mathrm{Cl}-\mathrm{N}_{\mathrm{O}}$ & & 0.10 & $(5.9)$ \\
\hline
\end{tabular}

modified by chloride solvation than the more robust pure PAN sponge structure.

As in PAN:PACl, electrostatic interactions between chloride and the cation ammonium are strongest in the EtAN:EtACl mixture, and dictate the overall structure. For EtAN:EtACl the $\mathrm{Cl} \cdots \mathrm{N}$ and $\mathrm{N} \cdots \mathrm{N}_{\mathrm{O}} g_{i j}(r)$ distributions both have peaks at $3.6 \AA$, but the peak in the $\mathrm{Cl} \cdots \mathrm{N} g_{i j}(r)$ is much sharper and almost twice as intense, indicating stronger attractions between the cation and the smaller, harder, chloride ion than nitrate. As in PAN:PACl, strong interactions between cation charge groups and the relatively small chloride anion result in the peak in the $\mathrm{N} \cdots \mathrm{N} g_{i j}(r)$ distribution shifting to smaller distances. The peak in the $\mathrm{Cl} \cdots \mathrm{O}_{\mathrm{H}} g_{i j}(r)$ function reveals strong interactions between chloride anions and cation hydroxyl groups, and each chloride is coordinated by 2.44 hydroxyl groups. The $\mathrm{Cl} \cdots \mathrm{O}_{\mathrm{H}}$ $g_{i j}(r)$ peak maximum lies at slightly lower separation $(3.33 \AA)$ than $\mathrm{Cl} \cdots \mathrm{N}(3.63 \AA)$ which is due to either differences in hydrogen bonding (discussed below) or steric effects relating to the increased number of protons bound to the ammonium $\mathrm{N}$ than alcohol $\mathrm{O}$.

The $\mathrm{N}-\mathrm{Cl}$ coordination number is higher in the EtAN:EtACl mixture (3.53) than in the PAN:PACl mixture (2.90), and the coordination number for chloride anions around the ammonium N $(\mathrm{N}-\mathrm{Cl})$ is 0.53 in EtAN:EtACl compared to 0.44 PAN:PACl. In pure EtAN, the ethanolammonium hydroxyl group disrupts solvophobic interactions between the cation alkyl chains. ${ }^{23}$ 
In the mixture, this means ethanolammonium cations are free to adopt conformations that maximise favourable charge-charge interactions with chloride relatively unencumbered by the need to segregate cation alkyl chains, resulting in higher coordination numbers than for PAN:PACl. This raises the question as to whether ethanolammonium preferentially interacts with chloride via either its alcohol or ammonium groups, or both simultaneously in a bidentate fashion.

Bidentate binding ethanolammonium to chloride requires the cation adopt a gauche or eclipsed conformation. The $\mathrm{O}_{\mathrm{H}^{-}}-\mathrm{C}_{2}-$ $\mathrm{C}_{1}-\mathrm{N}$ dihedral angle ( $c f$. Fig. S5 in the ESI $\dagger$ ) distribution shows none of the distinct trans and gauche peaks seen in PAN conformers (Fig. S4, ESI $\dagger$ ), but has sharp (but weak) peaks at $350^{\circ}$ and $240^{\circ}$ and a broader peak centred around $100^{\circ}$. This angle distribution for EtAN:EtACl also differs markedly from that of pure EtAN, also shown in Fig. S5 (ESI $\dagger$ ), again demonstrating the pronounced effect of chloride on the EtAN nanostructure. Addition of EtACl increases the probability of eclipsed conformations in the $\mathrm{EtA}^{+}$ion, while the peaks at $100^{\circ}$ and $240^{\circ}$ are indicative of preference for the gauche conformer, and the trans conformer probability is correspondingly reduced. The bond angle distribution for $\mathrm{O}_{\mathrm{H}} \cdots \mathrm{Cl} \cdots \mathrm{N}$ shows a pronounced peak at $40^{\circ}$ (cf. Fig. S6, ESI $\dagger$ ), which is not seen in corresponding distributions for either $\mathrm{O}_{\mathrm{H}} \cdots \mathrm{Cl} \cdots \mathrm{O}_{\mathrm{H}}$ or $\mathrm{N} \cdots \mathrm{Cl} \cdots \mathrm{N}$, suggesting a bidentate arrangement. Combining this with the peak $\mathrm{Cl} \cdots \mathrm{O}_{\mathrm{H}}$ $(3.3 \AA)$ and $\mathrm{Cl} \cdots \mathrm{N}(3.6 \AA)$ separations (Fig. 7B) yields an intramolecular $\mathrm{N} \cdots \mathrm{O}_{\mathrm{H}}$ distance of $\sim 2.4 \AA$, which corresponds to a pronounced peak in the intramolecular $g_{i j}(r)$ function for $\mathrm{N} \cdots \mathrm{O}_{\mathrm{H}}$ distances (Fig. S7, ESI $\dagger$ ). These results indicate a weak preference for bidentate binding of ethanolammonium to chloride.

Strong interactions between ethanolammonium and chloride markedly change nitrate-cation interactions in the EtAN:EtACl mixture compared to pure EtAN. ${ }^{23}$ The peak in the $\mathrm{N} \cdots \mathrm{N}_{\mathrm{O}} g_{i j}(r)$ correlation (Fig. 7B) is weaker in the EtAN:EtACl mixture, and the $\mathrm{N}_{\mathrm{O}}-\mathrm{N}$ and $\mathrm{N}-\mathrm{N}_{\mathrm{O}}$ coordination numbers of 2.80 and 2.38 (respectively) are $\sim 19 \%$ and $31 \%$ lower than in pure EtAN. By contrast, the $\mathrm{O}_{\mathrm{H}} \cdots \mathrm{N}_{\mathrm{O}}$ correlation peak lies at shorter separations in EtAN:EtACl (3.36 $\AA$ ) than EtAN (3.70 $)$, is much more pronounced, and the $\mathrm{N}_{\mathrm{O}}-\mathrm{O}_{\mathrm{H}}$ coordination number is increased by $\sim 40 \%$ in the mixture to 3.05 . This shows that the nitrate is partially displaced from the volume around the cation ammonium group by the chloride and into the coordination sphere of the alcohol group, with which it can hydrogen bond. Accordingly, interactions and correlations between cation hydroxyl groups are reduced in the mixture compared to pure EtAN (Fig. 7B). Each hydroxyl group is coordinated by 0.32 chlorides, and $\mathrm{O}_{\mathrm{H}}-\mathrm{O}_{\mathrm{H}}$ coordination numbers are reduced from 0.97 to 0.40 (Table 3 ).

This redistribution of nitrate anions eliminates the weak peak at $3.35 \AA$ in the $\mathrm{N}_{\mathrm{O}} \cdots \mathrm{N}_{\mathrm{O}} g_{i j}(r)$ correlation for pure EtAN. In pure EtAN, $\sim 4$ nitrate anions interact with each ammonium group, and stack to minimise repulsions between anions while maintaining their interactions with cation ammonium groups in a similar fashion as described above for pure PAN ${ }^{13}$ and the PAN:PACl mixture. In the EtAN:EtACl mixture, fewer nitrates interact with each cation charge group, which means anions are further apart. This removes the requirement for anion stacking.

The weak correlations at short distances in the pure EtAN carbon-carbon $g_{i j}(r)$ functions are absent in the EtAN:EtACl mixture. Solvophobic attractions between ethylammonium alkyl chains are weak in pure EtAN and are completely dominated by attractions between ethylammonium and chloride in EtAN:EtACl. The $g_{i j}(r)$ functions for $\mathrm{Cl} \cdots \mathrm{Cl}$ and $\mathrm{Cl} \cdots \mathrm{N}_{\mathrm{O}}$ correlations lack well defined peaks like those found in PAN and PAN:PACl.
A.

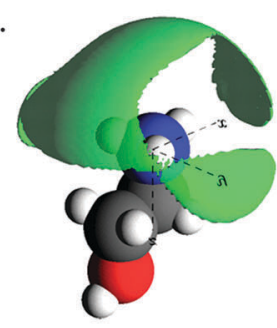

$\mathrm{Cl} @ \mathrm{~N}$

$0-4.5 \AA$

C.

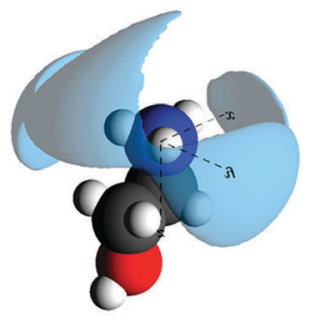

$\mathrm{N}_{\mathrm{O}} @ \mathrm{~N}$
$0-4.5 \AA$
D.

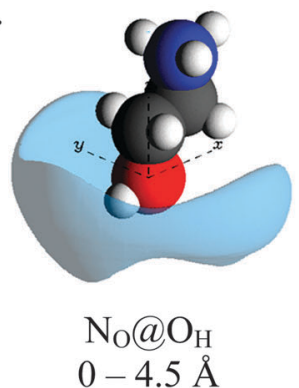

B.

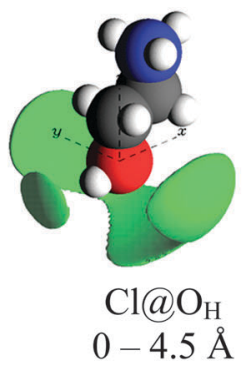

E.

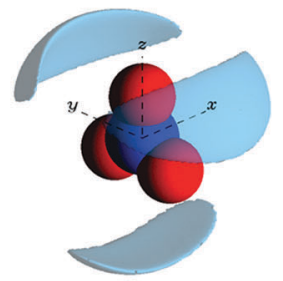

$\mathrm{N} @ \mathrm{~N}_{\mathrm{O}}$

$0-4.0 \AA$

Fig. 8 Spherical density function (SDF) plots for chloride-cation, anion-cation and cation-cation correlations in a 15 mol\% EtAN:EtACl mixture. All plots show the $20 \%$ isosurface for the distribution. Cut-off radii used for each plot are given below the plot. 
This is because in a clustered morphology anions are better dispersed than in a sponge structure.

Fig. 8 shows SDF plots for chloride and nitrate ions around the ammonium and hydroxyl polar centres in the $15 \mathrm{~mol} \%$ EtAN:EtACl mixture, with the central $\mathrm{EtA}^{+}$ion arbitrarily represented in its trans conformation. The SDF plots showing packing of chloride anions around the cation ammonium group (Cl@N) as a broad lobe sitting behind the ammonium group (above the $\mathrm{C}_{1}-\mathrm{C}_{2}$ axis) which extends over the ammonium group to the front of the cation. Additionally, smaller lobes are present on either side of the ammonium group adjacent to the ammonium protons. This is similar to the PAN:PACl system, but is more symmetrical as EtAN lacks solvophobic segregation of alkyl chains. The SDF plot for chloride around the hydroxyl group $\left(\mathrm{Cl} @ \mathrm{O}_{\mathrm{H}}\right)$ is similar to $\mathrm{Cl} @ \mathrm{~N}$, only the lobe directly above the $\mathrm{O}_{\mathrm{H}}$ atom (in the $\mathrm{C}_{2}-\mathrm{O}_{\mathrm{H}}$ axis) is smaller. In both distributions, the lobes located above the $\mathrm{C}_{1}-\mathrm{C}_{2}$ axis and to either side of the cation are consistent with chloride anions interacting with the cations in both a monodentate and bidentate fashion, while the lobes located in front of the $\mathrm{N}$ and $\mathrm{O}_{\mathrm{H}}$ atoms are consistent only with monodentate arrangements.

The $\mathrm{N}_{\mathrm{O}} @ \mathrm{~N}$ SDF plot has a similar distribution to the $\mathrm{Cl} @ \mathrm{~N}$ plot, however the lobe does not extend as completely over the cation $\mathrm{N}$ atom and the lobes adjacent to the ammonium protons are much larger. This is because strong interactions between chloride and cation ammonium groups results in displacement of nitrate anions. Lobes are also present in the $\mathrm{N}_{\mathrm{O}}$ @N SDF plot above and to either side of the $\mathrm{C}_{2}-\mathrm{O}_{\mathrm{H}}$ axis. As with the $\mathrm{Cl} @ \mathrm{~N}$ plot, these lobes are consistent with cations interacting with the anions in both a monodentate and bidentate fashion. Unlike the $\mathrm{N}_{\mathrm{O}} @ \mathrm{~N}$ SDF plot, the lobe in $\mathrm{N}_{\mathrm{O}} @ \mathrm{O}_{1} \mathrm{SDF}$ only wraps around the front of the $\mathrm{O}_{\mathrm{H}}$ atom, with the lobe being largest directly adjacent to the hydroxyl $\mathrm{H}_{\mathrm{O}}$ atom. This means that cations interact with nitrate anions primarily in a monodentate fashion, unlike chloride where a significant number of interactions are bidentate.

Anion around anion stacking arrangements are not presented. This is because the EtAN:EtACl mixture lacks a well-defined polar domain meaning anions are well dispersed and thus poorly correlated; the $\mathrm{N}_{\mathrm{O}}-\mathrm{N}_{\mathrm{O}}$ coordination number is 0.47 and the $\mathrm{Cl}-\mathrm{N}_{\mathrm{O}}$ coordination number is just 0.1 .

The nanostructure of pure EtAN has a clustered morphology that results from electrostatic interactions between charge groups, hydrogen bonding between the ammonium, nitrate, and hydroxyl groups, inducing weak solvophobic interactions between cation alkyl chains. In the EtAN:EtACl mixture, attractions between chloride and the ethanolammonium polar groups group dominate all other effects, dictating the liquid nanostructure despite only accounting for $15 \%$ of the anions. Cations dominate the volume around each chloride and can (dynamically) interact with the chloride in a monodentate fashion via either their ammonium or alcohol group, or through both in a bidentate eclipsed or gauche conformation, with bidentate the arrangement marginally preferred. The strength of the associations between cations and chloride affects the longer-range liquid nanostructure in neighbouring ions, even though they are not directly interacting with chloride. Thus, while both the pure EtAN and EtAN:EtACl mixture are clustered, the weak solvophobic association between ethanolammonium ions in pure EtAN are further attenuated by the strength of electrostatic interactions with chloride. This leads to the pronounced reduction in the correlation length derived from the peak position in the $\mathrm{d}_{4}$-EtAN:EtACl contrast (Fig. 2B).

In both ethanolammonium and propylammonium nitrate ILs, the average ammonium-nitrate distance is increased and the correlation between these ions reduced by the addition of chloride, which binds preferentially and at short distances to the cation. Chloride also favours gauche and eclipsed cation conformations in the mixtures; in EtAN solution, this is seen through an identifiable bidentate coordination of chloride to both ammonium and hydroxyl groups, and in PAN through changes in the local environment of the terminal methyl. Both of these lead to significant changes in the liquid nanostructure compared to the pure ILs. This decreases the correlation length and weakens the bicontinuous amphiphilic nanostructure in PAN, and reduces the extent of clustering in the weaklystructured and borderline "non-amphiphilic" EtAN. Such changes in nanostructure are expected to strongly affect the performance of these ILs as solvents for various classes of solutes, providing a new avenue by which to tune their properties. We would expect, for example, that the maximum chain length of miscible aliphatic alcohols which depends on IL apolar domain size, ${ }^{84}$ would be reduced by chloride addition.

It is perhaps unsurprising that this result contrasts with our earlier study of lithium ion effects by addition of $\mathrm{LiNO}_{3}$ to EAN and EtAN. ${ }^{55}$ Added $\mathrm{Li}^{+}$is strongly solvated by nitrate and hence directly affects only the polar domains of the IL, whereas here the strong interactions are between chloride and the cation, which are the main scaffolds of the liquid nanostructure in these ILs. Nanostructure in ILs with amphiphilic ${ }^{85}$ or fluorous anions ${ }^{33,86}$ might be affected quite differently.

Counterion-specificity is of course well-known to manifest in numerous aqueous amphiphile phases, ${ }^{87,88}$ and has recently been documented in ionic micelle systems in these and other ILs. ${ }^{89}$ Whereas in aqueous systems, an understanding of hydration and other contributions to ion-specificity is welldeveloped, ${ }^{90,91}$ in ILs this is as yet in its infancy. The subtle effects shown here to be exerted by chloride on liquid nanostructure suggest that there is much yet to be understood about how ILs act as solvents for simple electrolytes, as well as more complex mixtures. ${ }^{92-94}$

\section{Conclusions}

In earlier work we have shown that PAN has a well-defined, amphiphilic nanostructure consisting of interpenetrating (bicontinuous) networks of polar and apolar domains that percolate through the liquid. ${ }^{13}$ This nanostructure results from electrostatic interactions leading to the formation of polar regions from which the cation propyl chains are solvophobically excluded, and cluster into apolar domains. In EtAN, this solvophobic effect is disrupted and weakened by the addition of a 
terminal alcohol group to the cation, leading instead to a less well-defined, clustered arrangement. ${ }^{23}$ We have also shown that addition of 15 mol\% lithium nitrate to EAN (which is structurally similar to PAN) has little effect on nanostructure, with the lithium ions simply incorporated in to the polar domain. ${ }^{55}$ Dissolved lithium had a stronger effect on the nanostructure of EtAN; the presence of lithium caused the ethanolammonium to favour the trans conformer, which transforms the native clustered arrangement into a bicontinuous amphiphilic nanostructure. ${ }^{55}$ In this work we have probed how the chloride anion at the same concentration affects the nanostructures of PAN and EtAN.

In both PAN:PACl and EtAN:EtACl mixtures, the strongest interactions are between chloride and the ammonium cation. In PAN:PACl, solvophobic segregation of the cation alkyl chains is retained, but changes in cation arrangement alter the amphiphilic nanostructure compared to pure PAN. In EtAN, weak solvophobic attractions between cation alkyl chains are overwhelmed by chloride-cation interactions, which disrupts the clustered nanostructure of the native IL. Thus, in both mixtures, cation packing around the chloride ion templates a changed liquid nanostructure, despite its relatively low concentration.

In the PAN:PACl mixture, $\sim 3$ ammonium groups pack around each chloride ion. Cation alkyl chains respond by rotating to favour a gauche conformation within the apolar domains, resulting in a distorted trigonal planar arrangement of ammonium groups around $\mathrm{Cl}^{-}$. This shrinks the apolar domains and thereby reduces the periodicity of the amphiphilic nanostructure. A surprising consequence of this arrangement is that the cation alkyl chain terminal methyl groups are more strongly associated with the polar phase when chloride is present than in pure PAN.

The weaker nanostructure of EtAN means that attractions between chloride and the ethanolammonium charge centre and alcohol group swamp other interactions. Each chloride ion is coordinated by $\sim 3.5$ ammonium groups and $\sim 2.5$ alcohol groups. Unlike PAN, ethanolammonium can associate with chloride via either its ammonium or hydroxyl group in a monodentate arrangement, or via both groups if the cation adopts a bidentate eclipsed or gauche conformation. The dihedral angle distribution and intramolecular $g_{\mathrm{ij}}(r)$ functions for $\mathrm{EtA}^{+}$suggests that these conformations are marginally preferred compared with pure EtAN, which is suggestive of bidentate coordination.

\section{References}

1 M. J. Earle, J. Esperanca, M. A. Gilea, J. N. C. Lopes, L. P. N. Rebelo, J. W. Magee, K. R. Seddon and J. A. Widegren, The distillation and volatility of ionic liquids, Nature, 2006, 439, 831-834.

2 D. R. MacFarlane and K. R. Seddon, Ionic liquids - Progress on the fundamental issues, Aust. J. Chem., 2007, 60, 3-5.

3 M. J. Earle and K. R. Seddon, Ionic liquids. Green solvents for the future, Pure Appl. Chem., 2000, 72, 1391-1398.

4 C. A. Angell, N. Byrne and J.-P. Belieres, Parallel developments in aprotic and protic ionic liquids: Physical chemistry and applications, Acc. Chem. Res., 2007, 40, 1228-1236.
5 M. Freemantle, Designer solvents - Ionic liquids may boost clean technology development, Chem. Eng. News, 1998, 76, 32-37.

6 R. Hayes, G. G. Warr and R. Atkin, Structure and Nanostructure in Ionic Liquids, Chem. Rev., 2015, 115, 6357-6426.

7 P. L. Short, Out of the Ivory Tower, Chem. Eng. News, 2006, 84, 7.

8 M. Armand, F. Endres, D. R. MacFarlane, H. Ohno and B. Scrosati, Ionic-liquid materials for the electrochemical challenges of the future, Nat. Mater., 2009, 8, 621-629.

9 H. Li, R. J. Wood, M. W. Rutland and R. Atkin, An ionic liquid lubricant enables superlubricity to be "switched on" in situ using an electrical potential, Chem. Commun., 2014, 50, 4368-4370.

10 R. Á. Asencio, E. D. Cranston, R. Atkin and M. W. Rutland, Ionic Liquid Nanotribology: Stiction Suppression and Surface Induced Shear Thinning, Langmuir, 2012, 28, 9967-9976.

11 R. Hayes, N. Borisenko, B. Corr, G. B. Webber, F. Endres and R. Atkin, Effect of dissolved LiCl on the ionic liquid-Au(111) electrical double layer structure, Chem. Commun., 2012, 48, 10246-10248.

12 H. Li, P. K. Cooper, A. E. Somers, M. W. Rutland, P. C. Howlett, M. Forsyth and R. Atkin, Ionic Liquid Adsorption and Nanotribology at the Silica-Oil Interface: Hundred-Fold Dilution in Oil Lubricates as Effectively as the Pure Ionic Liquid, J. Phys. Chem. Lett., 2014, 5, 4095-4099.

13 R. Hayes, S. Imberti, G. G. Warr and R. Atkin, Pronounced sponge-like nanostructure in propylammonium nitrate, Phys. Chem. Chem. Phys., 2011, 13, 13544-13551.

14 R. Atkin and G. G. Warr, The smallest amphiphiles: Nanostructure in protic room-temperature ionic liquids with short alkyl groups, J. Phys. Chem. B, 2008, 112, 4164-4166.

15 R. Hayes, S. Imberti, G. G. Warr and R. Atkin, The Nature of Hydrogen Bonding in Protic Ionic Liquids, Angew. Chem., Int. Ed., 2013, 52, 4623-4627.

16 A. Triolo, O. Russina, H. J. Bleif and E. Di Cola, Nanoscale segregation in room temperature ionic liquids, J. Phys. Chem. B, 2007, 111, 4641-4644.

17 C. Hardacre, J. D. Holbrey, C. L. Mullan, T. G. A. Youngs and D. T. Bowron, Small angle neutron scattering from 1-alkyl3-methylimidazolium hexafluorophosphate ionic liquids ([C(n)mim][PF6], n = 4, 6, and 8), J. Chem. Phys., 2010, 133, 7.

18 T. L. Greaves, D. F. Kennedy, S. T. Mudie and C. J. Drummond, Diversity Observed in the Nanostructure of Protic Ionic Liquids, J. Phys. Chem. B, 2010, 114, 10022-10031.

19 J. J. Segura, A. Elbourne, E. J. Wanless, G. G. Warr, K. Voitchovsky and R. Atkin, Adsorbed and near surface structure of ionic liquids at a solid interface, Phys. Chem. Chem. Phys., 2013, 15, 3320-3328.

20 B. McLean, H. Li, R. Stefanovic, R. J. Wood, G. B. Webber, K. Ueno, M. Watanabe, G. G. Warr, A. Page and R. Atkin, Nanostructure of $[\mathrm{Li}(\mathrm{G} 4)]$ TFSI and [Li(G4)] NO3 solvate ionic liquids at HOPG and $\mathrm{Au}(111)$ electrode interfaces as a function of potential, Phys. Chem. Chem. Phys., 2015, 17, 325-333. 
21 A. J. Page, A. Elbourne, R. Stefanovic, M. A. Addicoat, G. G. Warr, K. Voitchovsky and R. Atkin, 3-Dimensional atomic scale structure of the ionic liquid-graphite interface elucidated by AM-AFM and quantum chemical simulations, Nanoscale, 2014, 6, 8100-8106.

22 A. Elbourne, K. Voitchovsky, G. G. Warr and R. Atkin, Ion structure controls ionic liquid near-surface and interfacial nanostructure, Chem. Sci., 2015, 6, 527-536.

23 R. Hayes, S. Imberti, G. G. Warr and R. Atkin, Amphiphilicity determines nanostructure in protic ionic liquids, Phys. Chem. Chem. Phys., 2011, 13, 3237-3247.

24 R. Hayes, S. Imberti, G. G. Warr and R. Atkin, Effect of Cation Alkyl Chain Length and Anion Type on Protic Ionic Liquid Nanostructure, J. Phys. Chem. C, 2014, 118, 13998-14008.

25 H. K. Kashyap, J. J. Hettige, H. V. R. Annapureddy and C. J. Margulis, SAXS anti-peaks reveal the length-scales of dual positive-negative and polar-apolar ordering in room-temperature ionic liquids, Chem. Commun., 2012, 48, 5103-5105.

26 J. Lopes and A. A. H. Padua, Nanostructural organization in ionic liquids, J. Phys. Chem. B, 2006, 110, 3330-3335.

27 A. Triolo, O. Russina, B. Fazio, R. Triolo and E. Di Cola, Morphology of 1-alkyl-3-methylimidazolium hexafluorophosphate room temperature ionic liquids, Chem. Phys. Lett., 2008, 457, 362-365.

28 K. Binnemans, Ionic liquid crystals, Chem. Rev., 2005, 105, 4148-4204.

29 A. E. Bradley, C. Hardacre, J. D. Holbrey, S. Johnston, S. E. J. McMath and M. Nieuwenhuyzen, Small-angle X-ray scattering studies of liquid crystalline 1-alkyl-3-methylimidazolium salts, Chem. Mater., 2002, 14, 629-635.

30 J. De Roche, C. M. Gordon, C. T. Imrie, M. D. Ingram, A. R. Kennedy, F. Lo Celso and A. Triolo, Application of complementary experimental techniques to characterization of the phase behavior of $\mathrm{C}(16) \mathrm{mim}$ PF6 and C(14)mim PF6, Chem. Mater., 2003, 15, 3089-3097.

31 A. Triolo, O. Russina, R. Caminiti, H. Shirota, H. Y. Lee, C. S. Santos, N. S. Murthy and E. W. Castner, Comparing intermediate range order for alkyl- vs. ether-substituted cations in ionic liquids, Chem. Commun., 2012, 48, 4959-4961.

32 H. K. Kashyap, C. S. Santos, R. P. Daly, J. J. Hettige, N. S. Murthy, H. Shirota, E. W. Castner and C. J. Margulis, How Does the Ionic Liquid Organizational Landscape Change when Nonpolar Cationic Alkyl Groups Are Replaced by Polar Isoelectronic Diethers?, J. Phys. Chem. B, 2013, 117, 1130-1135.

33 T. L. Greaves, D. F. Kennedy, Y. Shen, A. Hawley, G. H. Song and C. J. Drummond, Fluorous protic ionic liquids exhibit discrete segregated nano-scale solvent domains and form new populations of nano-scale objects upon primary alcohol addition, Phys. Chem. Chem. Phys., 2013, 15, 7592-7598.

34 F. Bardak, D. Xiao, L. G. Hines, P. Son, R. A. Bartsch, E. L. Quitevis, P. Yang and G. A. Voth, Nanostructural Organization in Acetonitrile/Ionic Liquid Mixtures: Molecular Dynamics Simulations and Optical Kerr Effect Spectroscopy, ChemPhysChem, 2012, 13, 1687-1700.
35 M. Bester-Rogac, A. Stoppa and R. Buchner, Ion Association of Imidazolium Ionic Liquids in Acetonitrile, J. Phys. Chem. B, 2014, 118, 1426-1435.

36 T. Murphy, R. Hayes, S. Imberti, G. G. Warr and R. Atkin, Nanostructure of an ionic liquid-glycerol mixture, Phys. Chem. Chem. Phys., 2014, 16, 13182-13190.

37 A. S. Paluch, C. A. Vitter, J. K. Shah and E. J. Maginn, A comparison of the solvation thermodynamics of amino acid analogues in water, 1-octanol and 1-n-alkyl-3-methylimidazolium bis(trifluoromethylsulfonyl)imide ionic liquids by molecular simulation, J. Chem. Phys., 2012, 137, 184504.

38 G. Rai and A. Kumar, Elucidation of Ionic Interactions in the Protic Ionic Liquid Solutions by Isothermal Titration Calorimetry, J. Phys. Chem. B, 2014, 118, 4160-4168.

39 O. Russina, M. Macchiagodena, B. Kirchner, A. Mariani, B. Aoun, M. Russina, R. Caminiti and A. Triolo, Association in ethylammonium nitrate-dimethyl sulfoxide mixtures: First structural and dynamical evidences, J. Non-Cryst. Solids, 2015, 407, 333-338.

40 A. Stoppa, J. Hunger, G. Hefter and R. Buchner, Structure and Dynamics of 1-N-Alkyl-3-N-Methylimidazolium Tetrafluoroborate plus Acetonitrile Mixtures, J. Phys. Chem. B, 2012, 116, 7509-7521.

41 Y. Z. Zheng, H. Y. He, Y. Zhou and Z. W. Yu, Hydrogenbonding interactions between BMIM BF4 and dimethyl sulfoxide, J. Mol. Struct., 2014, 1069, 140-146.

42 Y. Z. Zheng, N. N. Wang, J. J. Luo, Y. Zhou and Z. W. Yu, Hydrogen-bonding interactions between BMIM BF4 and acetonitrile, Phys. Chem. Chem. Phys., 2013, 15, 18055-18064.

43 M. Deetlefs, C. Hardacre, M. Nieuwenhuyzen, O. Sheppard and A. K. Soper, Structure of ionic liquid-benzene mixtures, J. Phys. Chem. B, 2005, 109, 1593-1598.

44 M. G. Del Popolo, C. L. Mullan, J. D. Holbrey, C. Hardacre and P. Ballone, Ion association in bmim PF6/naphthalene mixtures: An experimental and computational study, J. Am. Chem. Soc., 2008, 130, 7032-7041.

45 J. D. Holbrey, W. M. Reichert, M. Nieuwenhuyzen, O. Sheppard, C. Hardacre and R. D. Rogers, Liquid clathrate formation in ionic liquid-aromatic mixtures, Chem. Commun., 2003, 476-477.

46 R. M. Lynden-Bell, L. J. Xue, G. Tamas and E. L. Quitevis, Local structure and intermolecular dynamics of an equimolar benzene and 1,3-dimethylimidazolium bis (trifluoromethane)sulfonyl amide mixture: Molecular dynamics simulations and OKE spectroscopic measurements, J. Chem. Phys., 2014, 141, 044506.

47 S. R. Prabhu and G. B. Dutt, Rotational Diffusion of Nondipolar and Charged Solutes in Alkyl-Substituted Imidazolium Triflimides: Effect of $\mathrm{C} 2$ Methylation on Solute Rotation, J. Phys. Chem. B, 2014, 118, 9420-9426.

48 S. R. Prabhu and G. B. Dutt, Rotational Diffusion of Organic Solutes in 1-Methyl-3-octylimidazolium TetrafluoroborateDiethylene Glycol Mixtures: Influence of Organic Solvent on the Organized Structure of the Ionic Liquid, J. Phys. Chem. B, 2014, 118, 5562-5569.

49 S. R. Prabhu and G. B. Dutt, Rotational Diffusion of Nonpolar and Charged Solutes in Propylammonium 
Nitrate-Propylene Glycol Mixtures: Does the Organized Structure of the Ionic Liquid Influence Solute Rotation?, J. Phys. Chem. B, 2014, 118, 2738-2745.

$50 \mathrm{H}$. Shirota, Intermolecular/Interionic Vibrations of 1-Methyl3-n-octylimidazolium Tetrafluoroborate Ionic Liquid and Benzene Mixtures, J. Phys. Chem. B, 2013, 117, 7985-7995.

51 D. Wagle, G. Kamath and G. A. Baker, Elucidating Interactions Between Ionic Liquids and Polycyclic Aromatic Hydrocarbons by Quantum Chemical Calculations, J. Phys. Chem. C, 2013, 117, 4521-4532.

52 S. Caporali, C. Chiappe, T. Ghilardi, C. S. Pomelli and C. Pinzino, Coordination Environment of Highly Concentrated Solutions of CuII in Ionic Liquids through a Multidisciplinary Approach, ChemPhysChem, 2012, 13, 1885-1892.

53 P. D’Angelo, A. Zitolo, F. Ceccacci, R. Caminiti and G. Aquilanti, Structural characterization of zinc(II) chloride in aqueous solution and in the protic ionic liquid ethyl ammonium nitrate by $\mathrm{x}$-ray absorption spectroscopy, J. Chem. Phys., 2011, 135, 154509.

54 G. A. Giffin, A. Moretti, S. Jeong and S. Passerini, Complex Nature of Ionic Coordination in Magnesium Ionic LiquidBased Electrolytes: Solvates with Mobile $\mathrm{Mg}^{2+}$ Cations, J. Phys. Chem. C, 2014, 118, 9966-9973.

55 R. Hayes, S. A. Bernard, S. Imberti, G. G. Warr and R. Atkin, Solvation of Inorganic Nitrate Salts in Protic Ionic Liquids, J. Phys. Chem. C, 2014, 118, 21215-21225.

56 S. Jeremias, G. A. Giffin, A. Moretti, S. Jeong and S. Passerini, Mechanisms of Magnesium Ion Transport in Pyrrolidinium Bis(trifluoromethanesulfonyl)imide-Based Ionic Liquid Electrolytes, J. Phys. Chem. C, 2014, 118, 28361-28368.

57 T. Mendez-Morales, J. Carrete, S. Bouzon-Capelo, M. PerezRodriguez, O. Cabeza, L. J. Gallego and L. M. Varela, MD Simulations of the Formation of Stable Clusters in Mixtures of Alkaline Salts and Imidazolium-Based Ionic Liquids, J. Phys. Chem. B, 2013, 117, 3207-3220.

58 D. Monti, E. Jonsson, M. R. Palacin and P. Johansson, Ionic liquid based electrolytes for sodium-ion batteries: $\mathrm{Na}^{+}$ solvation and ionic conductivity, J. Power Sources, 2014, 245, 630-636.

59 F. Castiglione, A. Famulari, G. Raos, S. V. Meille, A. Mele, G. B. Appetecchi and S. Passerini, Pyrrolidinium-Based Ionic Liquids Doped with Lithium Salts: How Does $\mathrm{Li}^{+}$ Coordination Affect Its Diffusivity?, J. Phys. Chem. B, 2014, 118, 13679-13688.

60 C. Lawler and M. D. Fayer, The Influence of Lithium Cations on Dynamics and Structure of Room Temperature Ionic Liquids, J. Phys. Chem. B, 2013, 117, 9768-9774.

61 Z. Li, O. Borodin, G. D. Smith and D. Bedrov, Effect of organic solvents on li( + ) ion solvation and transport in ionic liquid electrolytes: a molecular dynamics simulation study, J. Phys. Chem. B, 2015, 119, 3085-3096.

62 H. J. Liu and E. Maginn, Effect of ion structure on conductivity in lithium-doped ionic liquid electrolytes: A molecular dynamics study, J. Chem. Phys., 2013, 139, 114508.
63 T. Mendez-Morales, J. Carrete, O. Cabeza, O. Russina, A. Triolo, L. J. Gallego and L. M. Varela, Solvation of Lithium Salts in Protic Ionic Liquids: A Molecular Dynamics Study, J. Phys. Chem. B, 2014, 118, 761-770.

64 B. G. Nicolau, A. Sturlaugson, K. Fruchey, M. C. C. Ribeiro and M. D. Fayer, Room Temperature Ionic Liquid-Lithium Salt Mixtures: Optical Kerr Effect Dynamical Measurements, J. Phys. Chem. B, 2010, 114, 8350-8356.

65 S. A. Niu, Z. Cao, S. Li and T. Y. Yan, Structure and Transport Properties of the LiPF6 Doped 1-Ethyl-2,3dimethyl-imidazolium Hexaftuorophosphate Ionic Liquids: A Molecular Dynamics Study, J. Phys. Chem. B, 2010, 114, 877-881.

66 N. Sanchez-Ramirez, V. L. Martins, R. A. Ando, F. F. Camilo, S. M. Urahata, M. C. C. Ribeiro and R. M. Torresi, Physicochemical Properties of Three Ionic Liquids Containing a Tetracyanoborate Anion and Their Lithium Salt Mixtures, J. Phys. Chem. B, 2014, 118, 8772-8781.

67 H. Asai, K. Fujii, K. Nishi, T. Sakai, K. Ohara, Y. Umebayashi and M. Shibayama, Solvation Structure of Poly(ethylene glycol) in Ionic Liquids Studied by High-energy X-ray Diffraction and Molecular Dynamics Simulations, Macromolecules, 2013, 46, 2369-2375.

68 J. Mondal, E. Choi and A. Yethiraj, Atomistic Simulations of Poly(ethylene oxide) in Water and an Ionic Liquid at Room Temperature, Macromolecules, 2014, 47, 438-446.

69 A. Triolo, O. Russina, U. Keiderling and J. Kohlbrecher, Morphology of poly(ethylene oxide) dissolved in a room temperature ionic liquid: A small angle neutron scattering study, J. Phys. Chem. B, 2006, 110, 1513-1515.

70 O. Werzer, G. G. Warr and R. Atkin, Conformation of Poly(ethylene oxide) Dissolved in Ethylammonium Nitrate, J. Phys. Chem. B, 2011, 115, 648-652.

71 T. Ueki and M. Watanabe, Polymers in Ionic Liquids: Dawn of Neoteric Solvents and Innovative Materials, Bull. Chem. Soc. Jpn., 2012, 85, 33-50.

72 H. M. Yau, S. T. Keaveney, B. J. Butler, E. E. L. Tanner, M. S. Guerry, S. R. D. George, M. H. Dunn, A. K. Croft and J. B. Harper, Towards solvent-controlled reactivity in ionic liquids, Pure Appl. Chem., 2013, 85, 1979-1990.

73 M. G. Del Popolo, J. Kohanoff and R. M. Lynden-Bell, Solvation structure and transport of acidic protons in ionic liquids: A first-principles simulation study, J. Phys. Chem. B, 2006, 110, 8798-8803.

74 L. Yu, J. Clifford, T. T. Pham, E. Almaraz, F. Perry, G. A. Caputo and T. D. Vaden, Conductivity, Spectroscopic, and Computational Investigation of $\mathrm{H}_{3} \mathrm{O}^{+}$Solvation in Ionic Liquid BMIBF 4 , J. Phys. Chem. B, 2013, 117, 7057-7064.

75 A. Podgoršek, M. Macchiagodena, F. Ramondo, M. F. Costa Gomes and A. A. H. Pádua, Glycine in 1-Butyl-3-Methylimidazolium Acetate and Trifluoroacetate Ionic Liquids: Effect of Fluorination and Hydrogen Bonding, ChemPhysChem, 2012, 13, 1753-1763.

76 T. Murphy, R. Atkin and G. G. Warr, Scattering from ionic liquids, Curr. Opin. Colloid Interface Sci., 2015, 20, 282-292. 
77 A. K. Soper, W. S. Howells and A. C. Hannon, ATLAS: analysis of time-of-flight diffraction data from liquid and amorphous samples, Rutherford Appleton Laboratory, Didcot, 1989.

78 A. K. Soper, Empirical potential Monte Carlo simulation of fluid structure, Chem. Phys., 1996, 202, 295-306.

79 A. K. Soper, Partial structure factors from disordered materials diffraction data: An approach using empirical potential structure refinement, Phys. Rev. B: Condens. Matter Mater. Phys., 2005, 72, 104204.

80 C. Hardacre, J. D. Holbrey, S. E. J. McMath, D. T. Bowron and A. K. Soper, Structure of molten 1,3-dimethylimidazolium chloride using neutron diffraction, J. Chem. Phys., 2003, 118, 273-278.

81 H. V. R. Annapureddy, H. K. Kashyap, P. M. De Biase and C. J. Margulis, What is the Origin of the Prepeak in the X-ray Scattering of Imidazolium-Based Room-Temperature Ionic Liquids?, J. Phys. Chem. B, 2010, 114, 16838-16846.

82 C. S. Santos, N. S. Murthy, G. A. Baker and E. W. Castner, Communication: X-ray scattering from ionic liquids with pyrrolidinium cations, J. Chem. Phys., 2011, 134, 121101.

83 J. J. Hettige, H. K. Kashyap, H. V. R. Annapureddy and C. J. Margulis, Anions, the Reporters of Structure in Ionic Liquids, J. Phys. Chem. Lett., 2013, 4, 105-110.

84 H. J. Jiang, P. A. FitzGerald, A. Dolan, R. Atkin and G. G. Warr, Amphiphilic Self-Assembly of Alkanols in Protic Ionic Liquids, J. Phys. Chem. B, 2014, 118, 9983-9990.

85 M. Macchiagodena, F. Ramondo, A. Triolo, L. Gontrani and R. Caminiti, Liquid Structure of 1-Ethyl-3-methylimidazolium Alkyl Sulfates by X-ray Scattering and Molecular Dynamics, J. Phys. Chem. B, 2012, 116, 13448-13458.

86 Y. Shen, D. F. Kennedy, T. L. Greaves, A. Weerawardena, R. J. Mulder, N. Kirby, G. H. Song and C. J. Drummond, Protic ionic liquids with fluorous anions: physicochemical properties and self-assembly nanostructure, Phys. Chem. Chem. Phys., 2012, 14, 7981-7992.

87 H. N. Patrick and G. G. Warr, Counterion Binding and Regulation of Interactions between Charged Bilayers, J. Phys. Chem., 1996, 100, 16268-16274.

88 S. Berr, R. R. M. Jones and J. S. Johnson, Effect of counterion on the size and charge of alkyltrimethylammonium halide micelles as a function of chain length and concentration as determined by small-angle neutron scattering, J. Phys. Chem., 1992, 96, 5611-5614.

89 A. Dolan, R. Atkin and G. G. Warr, The origin of surfactant amphiphilicity and self-assembly in protic ionic liquids, Chem. Sci., 2015, 6, 6189-6198.

90 W. Kunz, P. Lo Nostro and B. W. Ninham, The present state of affairs with Hofmeister effects, Curr. Opin. Colloid Interface Sci., 2004, 9, 1-18.

91 J. D. Morgan, D. H. Napper and G. G. Warr, Thermodynamics of Ion Exchange Selectivity at Interfaces, J. Phys. Chem., 1995, 99, 9458-9465.

92 M. W. Zhao, Y. N. Gao and L. Q. Zheng, Lyotropic liquid crystalline phases formed in binary mixture of 1-tetradecyl3-methylimidazolium chloride/ethylammonium nitrate and its application in the dispersion of multi-walled carbon nanotubes, Colloids Surf., A, 2010, 369, 95-100.

93 C. R. Lopez-Barron, M. G. Basavaraj, L. DeRita and N. J. Wagner, Sponge-to-Lamellar Transition in a Double-Tail Cationic Surfactant/Protic Ionic Liquid System: Structural and Rheological Analysis, J. Phys. Chem. B, 2012, 116, 813-822.

94 C. R. Lopez-Barron, D. C. Li, L. DeRita, M. G. Basavaraj and N. J. Wagner, Spontaneous Thermoreversible Formation of Cationic Vesicles in a Protic Ionic Liquid, J. Am. Chem. Soc., 2012, 134, 20728-20732. 